\title{
Biomedical Optics and Lasers
}

\author{
B. Cem Sener \\ Department of Oral and Maxillofacial Surgery \\ Faculty of Dentistry, Marmara University, Istanbul,
}

Turkey

\section{Introduction}

Electromagnetic energy is the source of life in our universe. Living organisms require energy to survive. Basic organisms provide this energy externally as a raw material (basic molecules like sugar) and convert it to energy (digestion of food). However some organisms, like green plants, can directly absorb radiation energy and store after a chemical conversion. Excessive energy is stored with a chemical reaction as adenine triphosphate (ATP) synthesis. Complex organisms digest more simple ones that contain readily synthetized ATP in an understanding of a food-chain. Under specific conditions complex organisms, partly, can absorb radiation energy and use it directly or store with ATP. Therefore, different bands located in certain parts of wide radiation energy spectrum can be used directly or indirectly to maintain our life. With this respect; interactions with radiation is mainly subjected within this context either with positive and negative ways, however both paths can be a matter of survival.

In that broad spectrum of radiation energy only a small part is visible (between 400 to $700 \mathrm{~nm}$ wavelength) for human beings (light). (Figure 1) However, mankind has converted or digitalized rest of spectrum to monitor and understand how it works for many purposes, like industry, navigation, communication, industry, research, military and medicine. Focus of this chapter is centered on a specific form of radiation, L.A.S.E.R. Amplified light generated by stimulated of emission can be defined as purified and well-disciplined form of radiation and therefore has a special importance in biomedical applications with its advanced features. Moreover; developments in optics, computer hardware and software, electronics and nanotechnology have widen the scope of LASER radiation in biomedical applications. This chapter aims to give a basic understanding of laser and its place as a solution for several issues struggled in clinical and laboratory environments of biomedical sciences. Innovative techniques centered on laser application are also given besides emphasized basic technical knowledge so that readers can develop their informative wallet to build up a vision for further steps both in bio- and engineering sciences. This would also have a collateral effect to prepare current reader as developers, researchers or users for the future.

\section{History}

Interaction of radiation energy with biologic systems is not a new concept and has been focus of human beings for millenniums. Evidences in ancient Greek writings for use of sun 
light as a therapy under "heliotherapy" term was first mentioned by Licht in 1983 [1]. During those ancient eras sun light (helios) or ancient Sun god was believed to have a blessing - healing (therapeutic) effect on living organisms. Healing effect of sun light has been a fundamental belief of esoteric teachings without any scientific basis. This belief continued during monotheistic religion for almost 400 years until rise of Holy Roman Empire. Even the suppression of ancient Sun worship by Christian orthodoxy; power of light has sustained in many teachings and illustrations of holy religions. Following development of observatory medical sciences in $18^{\text {th }}$ and $19^{\text {th }}$ centuries, benefits of sun light rediscovered for treatment of several diseases like scurvy, rickets, edema, rheumatic arthritis, dropsy, and depression caused by dark habitation environments during progress of coal industry. Increasing experimental sciences has proven that use of sun light has positive results in treatment of certain diseases and moreover development in optics and electromagnetic physics has brought evolvement of ultraviolet lamps and X-ray application in therapeutic and diagnostic medicine.

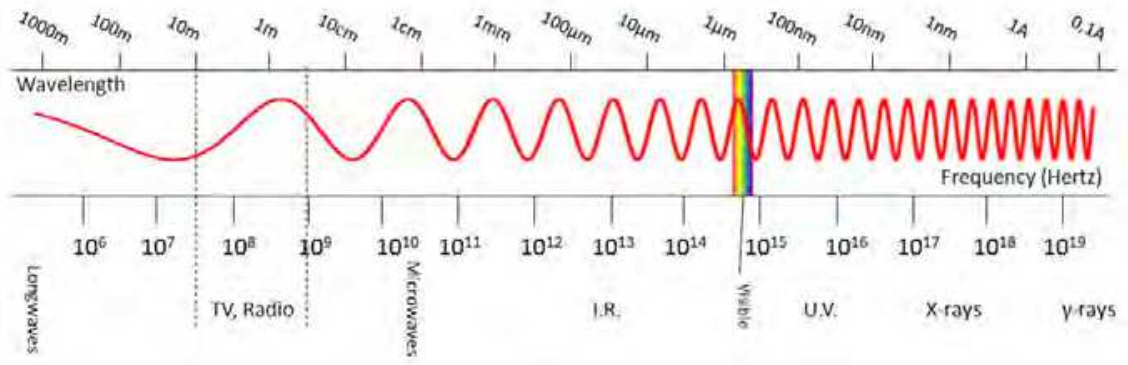

Fig. 1. Electromagnetic wave spectrum

Electromagnetic energy used in biotechnology has progressed with wider steps since "Zur Quantum Theorie der Strahlung" had been postulated by Albert Einstein in 1917. This explains the way how photoelectric amplification could emit a single frequency or stimulated emission which explains the way how laser works. In this direction; different groups worked on to improve more specialized and enhanced radiation energy source with augmented features next 40 years. In 1955 Gordon and coworkers described microwave amplification by stimulated radiation (MASER) using ammonia gas as the active medium, which can be termed as the ancestor of laser. Following, Schawlow and Townes (1958) applied this theory to light and named their invention as "optical maser". Although this development, Dr. Theodore Maiman (1960) pronounce "LASER" (Light Amplification by Stimulated Emission of Radiation) term for his device using ruby crystal to produce red laser beam at $694 \mathrm{~nm}$ wavelength. Following the 1960s and rapid development in laser technology including the use of wide range of alternative lasing media; new wavelengths have been introduced to the market as summarized in table 1.

\section{Laser physics - Components}

Underlying physical principles relevant laser irradiation is basically same for all laser types. Fundamental components of a laser energy producing devices are illustrated in figure 2 and as follows: 

a. Active lasing medium
b. Energy source
c. Optical (Resonating) cavity
d. Cooling system
e. Delivery system

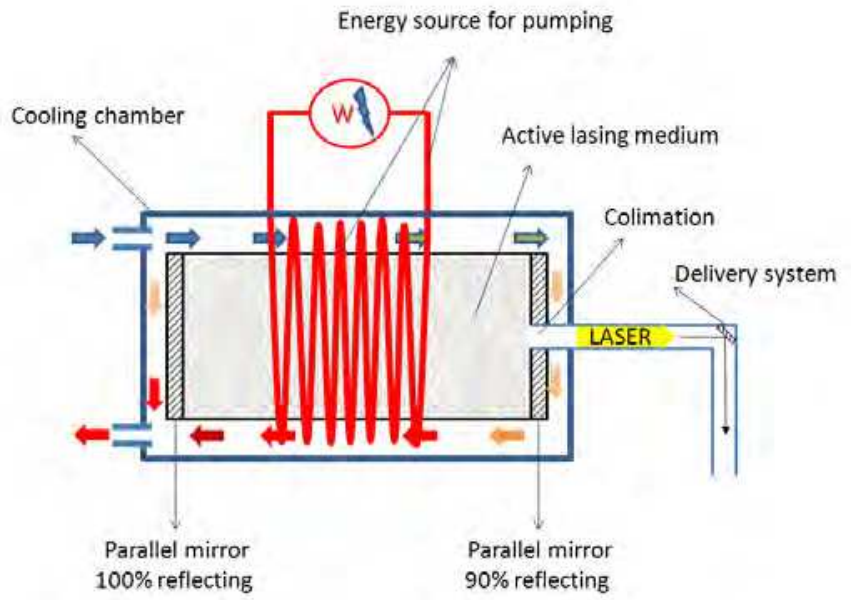

Fig. 2. Laser system illustration

\subsection{Active lasing medium}

Since the beginning of laser technology plenty of elements or mixtures are tested solely or in combination with another, regarding their potential to generate laser beam. Active lasing medium is a material, which can absorb energy given by the external source, to be excited through changes in the electrons of its atoms, molecules or ions, and finally emit this excessive energy as photons (Figure $3 \mathrm{a}, \mathrm{b}, \mathrm{c}$ ).

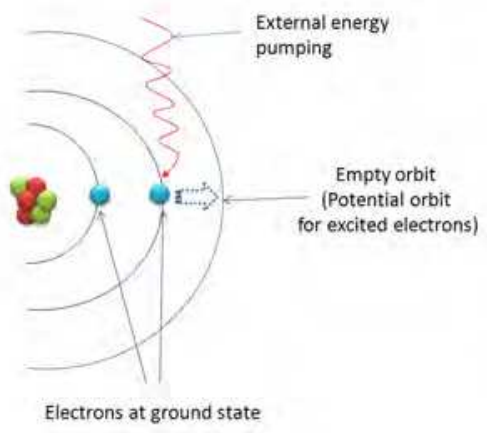

Fig. 3a. Stimulation (pumping phase). Excitation of the atom at ground state with external energy source. 


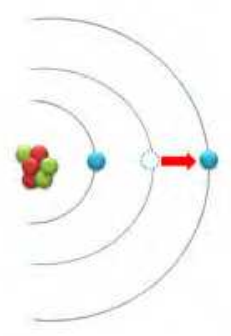

Fig. 3b. Excited atom at higher energy status is ready to emit radiation while returning to its ground status.

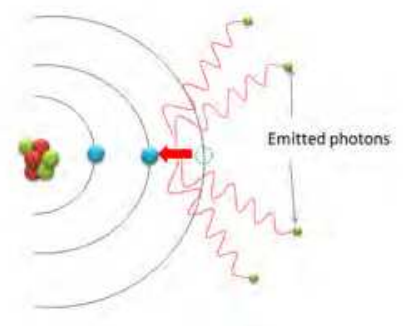

Fig. 3c. Photons are emitted while excited atom are returning to ground state following excitation phase.

Those releasing sequence (wavelength) is directly related with the type of lasing medium. Different lasing mediums can be used in combination to alter the predefined wavelength and/or carrier mediums that suspend the active lasing medium can also be excited and emit photons at different wavelength. This modification gives the possibility of generating two different laser wavelengths in one system, which can help to accelerate its effect on the target. Lasing mediums can be pure or in combination with a host material as a mixture or solution. Each medium has different photon emission nature that produces various wavelengths specific to the lasing medium. Features of laser beam is directly related with its wavelength (its place in the electromagnetic wave spectrum) and determined by its active lasing medium. Type of the laser is named with its wavelength on the radiation spectrum (like $810 \mathrm{~nm}$ ) or its active lasing medium (like diode laser). Active lasing mediums can be:

Gas

$\mathrm{CO}_{2}$, argon, krypton and combinations like helium-neon and excimer lasers like argon-fluoride (ArF) $193 \mathrm{~nm}$, krypton-fluoride $(\mathrm{KrF}) 248 \mathrm{~nm}$, xenon-chloride $(\mathrm{XeCl}) 308 \mathrm{~nm}$, xenon-fluoride (XeF) $353 \mathrm{~nm}$ are the most common types of gas lasers. Additionally xenon, nitrogen and carbon monoxide are used with different purposes. Additionally metal ions as a vapor can be used in combination with gas molecules to produce wide range of spectrum such as heliumsilver (HeAg) $224 \mathrm{~nm}$, helium-cadmium (HeCd) 441.563 nm, 325 nm, helium-mercury (HeHg) $567 \mathrm{~nm}, 615 \mathrm{~nm}$, helium-selenium (HeSe) between red and UV, strontium vapor $430.5 \mathrm{~nm}$, copper vapor $(\mathrm{Cu}) 510.6 \mathrm{~nm}, 578.2 \mathrm{~nm}$, neon-copper $(\mathrm{NeCu}) 248 \mathrm{~nm}$ and gold (Ag) vapor 627 $\mathrm{nm}$. Majority of the gas state laser mediums are pumped with electrical currency. 


\section{Liquid}

Liquid lasing mediums have one dye material, which is active counterpart of lasing (mostly a dye) and the solvent carrier (commonly an organic chemical solvent). Wide range of chemicals can be used, like copper, chromium, dyes, metallic salts. The medium can be fluent or even more dens (gel form). Coumarin, rhodamine and fluorescein are used as dye materials as a solution in chemical solvents such as methanol, ethanol or ethylene glycol. Periodic dielectrical stimulation of liquid crystal can be used for modulation of wavelength and may help modifying wave forms and frequencies of the generated laser beam.

\section{Solid}

Solid state lasing mediums are commonly in glass or crystal form. Active lasing material carried by a host material. With this purpose most common host material is yttriumaluminum-garnet (YAG) combination. Several active lasing materials like neodymium (Nd:YAG) $1.064 \mu \mathrm{m}$, erbium (Er:YAG) $2.94 \mu \mathrm{m}$, thulium (Tm:YAG) $2.0 \mu \mathrm{m}$, ytterbium (Yb:YAG) $1.03 \mu \mathrm{m}$, holmium (Ho:YAG) $2.1 \mu \mathrm{m}$ have been combined with this YAG carrier. Also yttrium lithium fluoride (YLF) with neodymium (Nd:YLF-1.047 and $1.053 \mu \mathrm{m}$ ), sapphire (aluminum oxide), like Ti:sapphire-650-1100 nm, Cr:sapphire (ruby laser-694.3 $\mathrm{nm}$ ), and silica glasses (Nd:Glass $-1.062 \mu \mathrm{m}$, ytterbium ${ }_{2} \mathrm{O}_{3}-1.03 \mu \mathrm{m}$, Promethium 147 doped phosphate glass (147 $\mathrm{Pm}^{+3}$ :Glass)- $933 \mathrm{~nm}, 1098 \mathrm{~nm}$, erbium doped and erbiumytterbium codoped glass-1.53-1.56 $\mu \mathrm{m}$ ) are used. As shown, proper types and amounts of dopants can help to generate different types of wavelengths. Commonly flash lamps or other kind of lasers are used for pumping in beam generation.

\section{Semiconductor}

Semiconductors are solid state materials using semiconductors as gain media for lasing. Light is emitted at an interband transition (conduction band). Most frequently used semiconductor gain mediums are: GaAs (gallium arsenide), AlGaAs (aluminum gallium arsenide), GaP (gallium phosphide), InGaP (indium gallium phosphide), GaN (gallium nitride), InGaAs (indium gallium arsenide), GaInNAs (indium gallium arsenide nitride), InP (indium phosphide) and GaInP (gallium indium phosphide). Combination of different elements enables to modulate the band gap energy. Their rage in wavelength spectrum is much of the visible, near-infrared and mid-infrared spectral region. Semiconductor lasers are commonly laser diodes and pumped with an electrical current in a region where an ndoped and a p-doped semiconductor material meet. On the other hand, optically pumped semiconductor lasers are also used, where carriers are generated by absorbed pump light, and quantum cascade lasers, where intraband transitions are utilized. Most semiconductor lasers generate a continuous output. Pulses can be generated with switching on the pump source only for certain time intervals, long enough to fulfill lasering process (quasicontinuous-wave operation), which allows to gain significantly enhanced powers. Ultrashort pulses can also be generated with mode locking (optical technique) or gain switching (modulating pump power).

Biologic materials

Following the description of green fluorescent protein, which was extracted from a jelly fish and has been shown as natural source biomolecules that emit back radiation after excitation 
[3] fluorescent proteins have evolved [4,5]. Several fluorescent biomolecules have been used as a lasing medium in vitro. Cells have recently been studied to be used as the source of laser light, which remained alive even after prolonged lasing action. Such biologic lasing units can be pointed out to be used for intracellular sensing, cytometry and imaging. [6] Light-emitting ability of green florescent protein has been shown as a lasing medium which can absorb blue light and then releasing identical particles of green light [7]. This development can be a promising medical treatment tool to irradiate a tumor with laser emitting cells or to mark them for imaging in the future.

\subsection{Stimulated emission of radiation concept}

Atoms of an active lasing medium are stimulated via external energy source (excitation mechanism) and its electrons jump-up from their balanced orbital state to a higher orbit by this absorbed incoming energy. Excitation phase help to transit the atoms to higher energy state, which is also unbalanced state (Figure $3 b$ ). Those atoms at high energy state return to their "ground state" spontaneously. Then, during transition of those charged electrons to their original orbits (lower energy states), they emit the excess energy as photons (Figure 3c). This emitting process generates identical photons at identical frequency and wavelength. This also provides perfect spatial and temporal harmony (in phase with time and space) of photons. Stimulation of atoms and emission of radiation, which has amplified properties than ordinary light, occurs in the resonator cavity and can be defined as the core of "Light Amplification by Stimulated Emission of Radiation-LASER" concept.

Wavelength of a laser defines its behavioral characteristics regarding interactions with target materials. Today we have a wide range of laser wavelengths and some are in visible light spectrum. Depending on type of the lasing medium, if the produced laser beam is within the visible light spectrum, its color varies.

\subsection{Energy source}

Excitation or pumping of active lasing medium is carried out with different methods, so that the atoms could be charged and transported to higher energy levels. As the pumping process start energy loading affects the atoms gradually. Some atoms excited totally, some less-excited and some are in ground sate. As the population of excited atoms is higher than others amplified radiation is emitted. Therefore, lasing medium can't emit radiation until pumping energy level reaches to the excitation threshold. Each lasing medium has its own stimulation method. With this purpose, pumping source should be powerful enough to reach emitting threshold to start working the system shortly after turning on the system, or multiple energy sources can be used simultaneously. This also helps to generate high energy output. Energy pumping systems use different sources in biomedical field.

\section{Electrical}

Electric current inside a noble gas medium creates glowing effect, which is also called "Electric glow discharge". It's simply used to pump diode lasers and semiconductor crystal lasers. Similarly free electron lasers and some excimer lasers can be pumped with electron beams. 


\section{Optical}

Optical pumping is used commonly through the lateral wall of the resonating cavity, which is also termed as "side-pumping". Earliest energy sources are flash lamps (xenon and krypton). Arch lamps (xenon, krypton, argon, neon, and helium) and flash lamps are still two of the most common optical pumping systems in use. Similarly some diode lasers also can be source of optical pumping and excite solid state or liquid dye lasing mediums alone or in combination of another pumping system. Correspondingly, sun beam has also been used as a pumping source of a laser [8]. Microwaves or radiofrequency can be an alternative source of pumping procedure.

\section{Chemical}

Chemical reactions can yield energy that can be used for energy pumping. Very high output power (up to megawatt) levels and continuous wave mode can be generated with chemical pumping technique. Chemical oxygen iodine laser (COIL)- $1.315 \mu \mathrm{m}$, all gas-phase iodine laser (AGIL)- $1.315 \mu \mathrm{m}$, and the hydrogen fluoride laser- 2.7-2.9 $\mu \mathrm{m}$ and deuterium fluoride lasers- $3.8 \mu \mathrm{m}$ are the examples of this system. Chemical or optical excitation can be used due to high control efficacy on energy pumping. Such high power lasers are mainly used in industry and military.

Gas dynamic excitation systems are used alone or in combination.

Energy pumping mechanism of this system is a thermodynamic process and depends on heat emission of a gas during sudden pressure decrease (adiabatic cooling). Preheated ad pressurized gasses (mostly $\mathrm{CO}_{2}$ ) is allowed to expand suddenly into a lower pressured medium with a supersonic velocity. This leads adiabatic cooling, which reduces the temperature and transfer the released energy to the active lasing material.

\subsection{Optical resonating cavity}

Of the main components of laser system is resonator cavity that surrounds active lasing medium and energy source for pumping. During excitation procedure, especially with high power laser systems, also excessive amount of heat is generated that may rise up to levels that may damage the system. Even low power laser systems may necessitate a cooling system around the lasing medium and energy source.

Photons generated in the cavity travel inside the cavity and reflected by two parallel mirrors one on either pole of lasing cavity, so that they can be reflected in between until a parallel beam profile is yielded (Figure 1). Of one is 100\% reflective while the other is $90-95 \%$ reflective due to collimation window that let the beam output leaving the cavity.

Since 1960's, geometry of the resonating cavities has been developing, due to the difficulties to produce entirely parallel mirrors. Also convex and concave mirror types have been introduced with the development in optical science and correspondingly cavity designs have evolved to obtain higher beam profile. However, even these advancements on resonating cavity designs or mirror geometries there are limitations for diode lasers due to their small size and production difficulties. [9] 


\subsection{Cooling system}

Present laser production process causes an important side-effect-excessive heating of the optical resonating cavity. Pumping source itself is a primary cause of thermal increase. Additionally, excitement of the active lasing medium can also lead increased resonation of lasing molecules, which means rise of temperature. Temperature of the resonating cavity can reach critical limit during operation, which may easily harm the system and cause severe damages. Therefore, heat control of the laser system mostly inevitable to avoid accidents. Laser cooling systems have been developed depending of the system requirements, while some low-power diode (semiconductor) systems may not necessitate cooling due to their low potential for heat production. More particularly; high repetition rate lasers requires a cooling system. This system generally comprises a closed coolant circulatory loop, which can be viewed in two pieces. First part of the loop is around the laser cavity and an annular coolant heat exchanger forming another portion of the loop. Coolant circulation means including an impeller extending into the loop adjacent an end of the annular heat exchanger are disposed concentrically within the core of the heat exchanger. Coolant absorbing heat generated by laser cavity transfers it to heat exchanger part to discharge externally. Secondary cooling layer can be necessary for high power systems that generate excessive heat.

Gases or liquids can be used as coolant. Water is presented as the more efficient and reliable cooling medium due to its high dissipation rate. However; liquid coolants have become less favorable due to their auxiliary requirements like filters, neutralizers, deionizers and expansion chambers for problem-free circulation in the closed loop environment. Moreover, corrosion and optical degradation associated with the use liquid coolants result in a considerable decrease in reliability and greatly increases requirements for maintenance. Furthermore axial flow impellers which are suitable for use in pumping compressed gases are inherently much more reliable than liquid pumps. Additionally, flashtube replacement in the presence of a liquid coolant is a wet dripping process. Of these issues another one is that excessive water pressure creates vibrations in the laser system.

The heat transport capacity of compressed nitrogen is comparable to that of liquid laser coolants but the effects of temperature extremes such as freezing boiling and expansion associated with liquid coolants are avoided. The compressed gas coolants have proved to be very efficient and therefore have increased greatly the life of the flashtubes.

\subsection{Delivery system}

Component of a laser system that is responsible to deliver the laser beam to, and/or the receiving the light from the source and transmit to the target is "delivery system". This can be viewed into two parts as: main light carrier and a piece responsible to focus or defocus beam on the target.

\section{a. Main carrier}

During manual operation clinicians require to aim the laser beam to a target area or point for desired shooting. Therefore, besides main working laser system a visible guide laser (mostly low power He-Ne laser) is required to help the user for proper aiming. Main carrier should allow entry and transmission of two different (guide laser and main operational 
laser) wavelengths simultaneously without any interference. The delivery systems should provide minimum energy output difference between source and tip for maximum power gain.

Most common types of the carrier systems are optical fibers and hollow waveguides. Fiber optic systems are consisted of a bare fiber core surrounded by fused cladding layer basically. Light travels through the lumen at less than a critical angle to be totally reflected whenever it hits the core-clad interface. Internal reflection allows the entire beam energy to be disseminated along the length of the fiber. Fiber systems are highly flexible and transmit radiation over long distances with constant beam diameter and minimal energy loss. This gives the possibility to transfer laser beam into an area, which is difficult to reach without a big access opening. Especially this is very helpful for surgical applications where removal of lesions located in an inner cavity or deep tissue is required. Such interventions (minimally invasive surgery) can be done via endoscopic systems from a small entry hole or without opening a large tissue cut (incision). Choice of fiber diameter can vary from $200 \mu \mathrm{m}, 300 \mu \mathrm{m}$ to $600 \mu \mathrm{m}$ for systems used in medical treatments. It should be considered that widening the laser beam to a wider lumen would lead divergence and spreading the output onto a larger spot size. This would be helpful to reduce the power on the target surface. On contrary; using fibers at thinner diameter keeps energy density at high level on the target or allows application of the laser beam into a narrow spaces, like a tooth canal. Though fiber optic systems are capable to transmit laser energy with minimal loss, recent efforts on composition of fiber optic system have been given to improve these features.

Clinician, with fiber systems, is capable to use the beam in contact mode without any applicator device. Operator can touch the fiber tip on target tissue and directly give the energy to the tissue, so the operation can be fulfilled with minimal energy loss and highest efficacy on the target. This application method circumvents spreading of energy to wider tissue surface that permits the surgeon to make an incision with minimal tissue damage.

Hollow waveguide is the alternative light transportation system. Following the beam output is expanded with an upcollimator, laser beam enters in to a hollow tube with reflective inner layer. Straight beam is directed to the target via articulating joints with reflective mirrors. Reflecting mirrors cause loss of power until it reaches to the target. During the travel of laser light in the hollow waveguide it expands and though lenses focusing can be a problem to keep the power loss at minimum level. This delivery system necessitates use of applicators for focusing. $\mathrm{CO}_{2}$ and Er lasers commonly use this system.

\section{b. Applicator}

Laser beam transmitted via carrier system reaches an applicator (a hand-piece or microscope) that adjust (mostly focus) beam profile and output according to the requirements of application. Applicator can focus the beam at micro scale, so that operations can be performed at the level of a single cell. Under the description of minimally invasive surgery; lasers have in principle the capability to cut a cell or restructuring of target tissue [10] Microbeam allows highly precise noncontact placement of foreign materials into targeted cells without compromising cell viability, which has been extremely difficult task for conventional techniques. Laser assisted delivery of exogenous material into a specific 
area of three-dimensional tissue, will help to understand the functioning of cellular structure or understand physiologic turn-overs and pathologic changes of a healthy cell [11]. This technique can be beneficial to mark some cells with traceable materials (dye, radioisotope, electromagnetic materials etc.) to follow their signals inside the body to explore their behavior. Exogenous material implantation can be a novel application in treatment of infectious diseases and cancer as well. Drug implanted immune system cells, which are responsible from body defense, can be used in the short future to destroy or mark the diseased area. Moreover; this method can be a promising for genetic studies.

Issues result due to collateral thermal damage to the surrounding living structures and protein denaturation has been overcome with ultrafast (picosecond) shots, so that a clear analysis possibility and problem-free wound healing could be yielded. [12, 13]. Use of such novel applications is highly essential in surgical procedures where sensitivity is required (like ophtamlology or central nervous system surgeries).

It's obvious that working at micro-scale would necessitate microscope use for proper visualization and application features. Therefore, laser systems to be used for micro-scale should be adapted to a microscope system. Some lens and mirror sequences can be used to provide a beam spot-size at micro scale. Micromanipulator devices can also be adapted to work with focused laser beam for precise operational performance. Robotic control feature opens a new era in laser applications with higher safety and more accuracy for the laser procedures that requires repeatability [14]. Automation of laser shooting with micromanipulator system also shortens the operation time and precise execution of surgical plans defined by the surgeon [15].

Major disadvantage with focusing is that the focus distance between the applicator tip and the tissue is constant. To work on a large object with a constant spot-size is almost impossible. A serial production unit it's easy to keep the optics fixed and move the object, however in the surgery room it's not wise. Therefore, surgeon should move the applicator connected to articulated tube system, which is not flexible and difficult to manipulate, to make a clean cut on the tissue. However; under this condition beam divergence and alignment can change and nonhomogenous irradiation profile is created. On the contrary, applicator provides a divergent beam profile to spread the beam on the target so that wider spot-size.

\section{Features of laser}

\subsection{Monocromatic}

Day (or ordinary bulb) light is a composition of different colors, which means it contains more than one wavelengths (for us: colors), in other term it's polychromatic (Figure 4). One of the differences from day light is that laser consists of only one wavelengthmonochromatic. Regarding the monochromacity; all energy is used to produce one wavelength at high power in a laser system, while same amount of energy is diverted and generates multiple wavelengths (polychromaticity) with ordinary light system. That makes laser energy more profitable to produce one wavelength higher effect on the target and more power with same energy. Also light emitting diodes (LED) are monochromatic. 


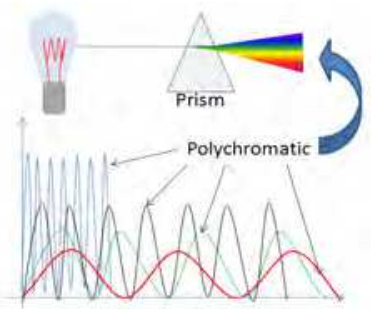

Ordinary light

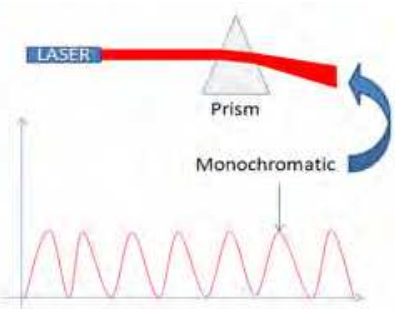

Laser

Fig. 4. Comparison of ordinary light and laser regarding mono-, or polychromocity.

\subsection{Collimation}

Ordinary light produced by bulb or fluorescent tube and light emitting diode (LED) etc. are radiated from one point uniformly in all directions. Some lens and mirror systems have been used to produce parallel beam with limited success and can't overcome divergence issue, while laser systems can produce almost parallel beam profile-collimated. (Figure 5) As the divergence ratio of beam rises, power density of beam spreads on a larger target area proportionally (inverse square law).

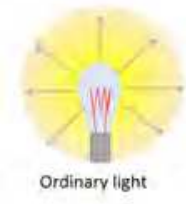

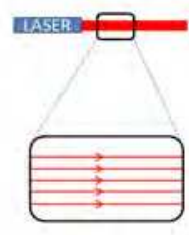

Laser photons are highly colimated

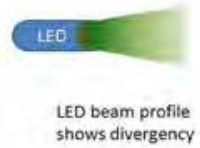

shows divergency

Fig. 5. Illustration shows emitted beam propertes of ordinary light, laser and LED light

Power density (irradiance) is also inversely proportional with square of distance between beam source and target. (Figure 6) Therefore, minimal divergence and use of all energy in one direction in a collimated beam lumen make laser able to transfer majority of output power to the target even at longer distances.

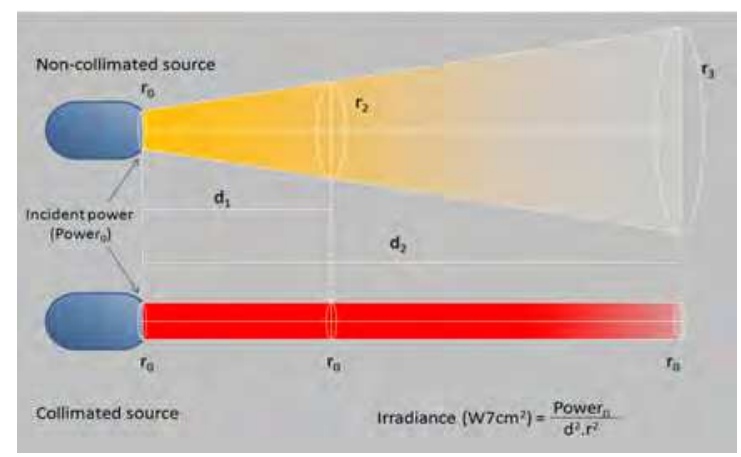

Fig. 6. Irradiace (power density) relationship with divergence and distance. 
If needed for special conditions (cutting or drilling materials or tissues), laser beam can be focused with lens systems so hat smaller spot-size can be yielded. Focusing the beam provides higher power density in the projection area on target and makes it possible to work at micro scale. In contrast; divergence can be created intentionally with defocusing lens systems, if needed to irradiate a wider area at single shot. However, it should be kept in mind that irradiating at defocused mode yields lower power density on target. This can be a practical way of reducing power density on the target, especially used in low level laser therapy. Or, defocusing the laser beam can be required to vaporize or process a large area in a short time. Higher power settings are should be used for this purpose.

\subsection{Coherent}

Photons of generated radiation energy have a releasing sequence and it also determines sequence of collision with the target. When laser is considered, generated photons resonating are synchronized. In other words; laser photons act together in one direction and hit the target simultaneously-coherent. On the other hand; non-laser sources (even LED beam) generate energy pulses sequentially and hit the target asynchronously (Figure 7a,b). That also explains the power of laser beam of which photons hits the target together at the same moment that brings additive effect. This feature of laser loads energy more easily at shorter exposure time and can be more destructive as well.

a. LED Source

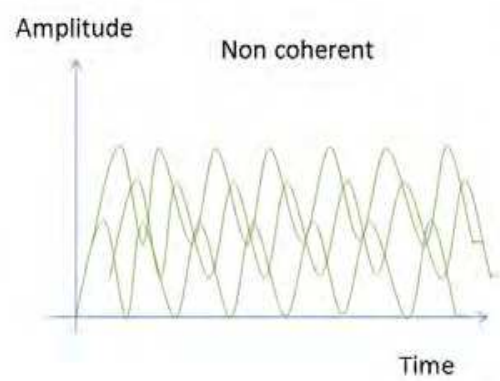

b. Laser Source

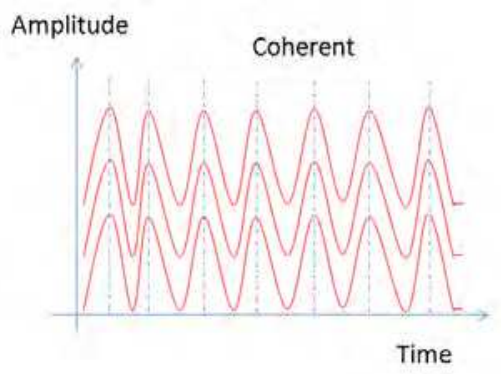

Fig. 7. Comparison of (a.) LED and (b.) laser sources regarding coherency.

\section{Modes of operation}

Generated laser beam can transfer the energy to the target. Given energy is directly related with the output amplitude and time. Laser systems emit the photons as long as the stimulation energy is given and this creates a continuous beam output, which is also named as continuous wave (CW) mode. $\mathrm{CW}$ output transfers energy to the target without interruption (Figure 8a) that creates high thermal effect at collision site. It's mostly used to destroy the aimed target by loading excessive energy and rise the temperature until it's burned out. On the other hand beam output can be delivered as interruptedly (pulsed mode) (Figure 8b).

Interruption (energy off) periods and pulse (energy on) durations can be modulated up to operator's purpose. Pulsed beam creates beating effect on the target that particularly benefited 


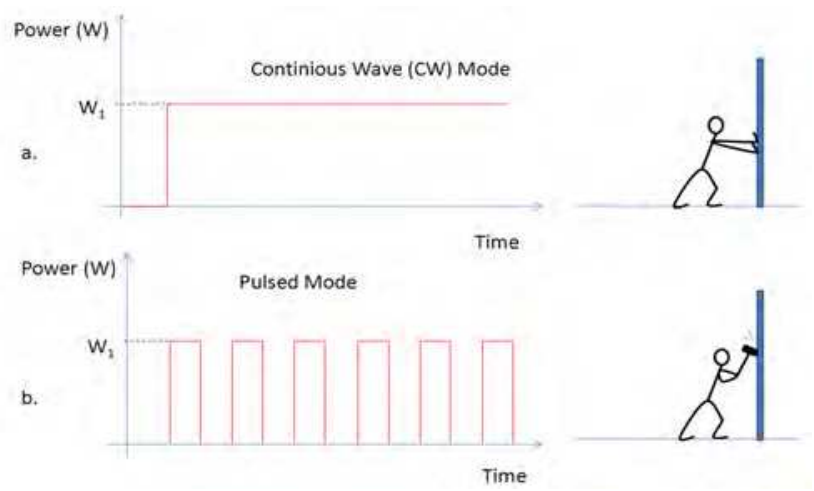

Fig. 8. Working modes of laser. Line graphic show (a.) continuos wave and (b.) pulsed beam profiles.

to destroy more solid materials, like ceramics, metals, bone or enamel of tooth, with less or no thermal effect. Depending on the length of on/off periods (pulse duration/intervals between pulses) transferred energy varies, as well as amplitude (Figure 9).

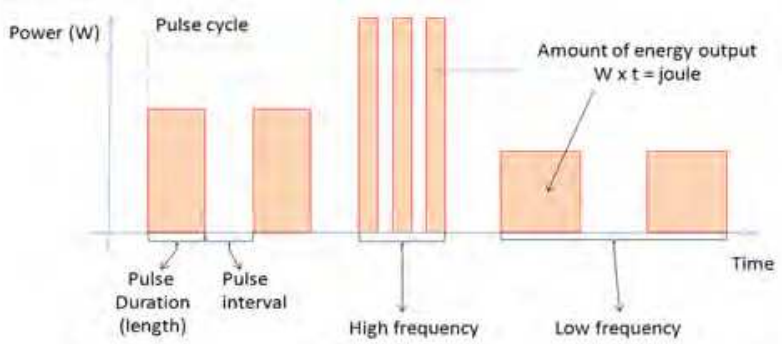

Fig. 9. Transferred energy amount is related with pulse duration and intervals between two pulses. Given energy is related with magnitude of power $(\mathrm{W})$ and pulse length in one pulse cycle, and repetition rate $(\mathrm{Hz})$ in unit time.

Though same amount of energy output is yielded; different pulse durations or repetitions rates affect the target in different ways. Longer pulses act like $\mathrm{CW}$ and tend to create more thermal damage on the target and heat it easily; while short pulses create mechanical beat effect with less or minor thermal damage like hammering. With this purpose shorter pulse rates (ultrafast lasers) were introduced at microsecond (10-6 second), nanosecond (10-9 second), picosecond (10-12 second) and femtosecond (10-15 second) ranges. Depending on the type of laser system optically methods like mode locking or pumping power modulation (gain switching) or Q switching techniques are used to generate pulse mode operations.

\section{Q (Quality) switch}

Q switch is a device placed inside the resonating cavity to prevent light from transmitting outside the resonating cavity basically. It comprises various attenuators to causes very low or rather high losses, respectively, for a laser beam sent through it. This helps to produce short intense pulses with high peak-power. Mostly they are used where the pulse duration is typically in the ultrafast range. 
High thermal effect is also used to destroy a tumor tissue or stop bleeding in the operation theater, killing microorganisms or welding of metals in industry but also in tissue closure instead of stiches. Welding technique will be detailed more under "Welding" topic. Additionally, it can be beneficial to heat deeper tissues, of course at lower power settings, intentionally for therapeutic purposes. This stimulates tissue regeneration and blood circulation on the target area, in cases when increased tissue metabolism is aimed to resolve inflammatory conditions [16]. Thus, pulsed energy at high frequencies and at proper amplitudes can breakdown molecular links of a substance in crystal form and may create cracks or even break them apart with micro-explosions. This helps the clinicians to remove hard tissues like bone, enamel or dentin of a tooth for treatment of different conditions.

\section{Light-tissue interaction}

Interaction phenomenon occurs between at least two entities. Interaction of two entities is a happening depends on natures of two components of interaction (laser and target). Basically, two kinds of interaction can be identified regarding the way of affected side: photon influence on tissue or tissue influence on photons. Regarding these interaction paths uses of electromagnetic energy on organisms can be roughly classified as:

1. Evaluation and research step: In other terms "tissue influence on photons"

2. Impaction step: "Photon influence on tissue" term describes; modification of tissue by laser photons' energy. In other terms; photon bombing modifies physical (photothermal effect) or chemical (photochemical effect) properties of target material. Type and degree of interaction is affected by several factors. power density,

a. Surgical aim: cutting, evaporation, coagulating, welding and dissecting, at high power settings.

b. Therapeutic aim: tissue regeneration via inducing ATP synthesis inside the cells, cell replication, blood circulation and, reduction of pain, tissue swelling (edema), etc. at low level power settings.

c. Production or modification of biomaterials: machining, processing, welding, coating and oxidizing.

Despite plenty efforts are given for the impaction step tissue-photon interactions, evaluation and research step is used to test results of clinical applications or material production steps. Use of biomedical optics and software simulations both for tissue impact and evaluation processes take place within this chapter to guide research scientists, professionals in biotechnology and medical health care.

Those features of laser beam which makes it a new tool in field of medicine. Diagnostic value of laser is also mentioned in this chapter as well as its therapeutic use. The professionals working in biomedical or health sciences will be able to learn about clinical uses of laser systems with clinical cases treated as well as gaining vision for the research and development branch of our science.

In order to understand the way how radiation energy is used in biomedical field; beamtarget material (tissue) interaction knowledge should be digested. Understanding the working modes, power density and wavelength variation help to realize what kind of effects laser energy has on the target materials. Regardless the type (wavelength) of laser, when the beam is directed to a tissue, it follows 4 action paths as it touches the surface reflection, transmission, scattering, absorption (Figure 10). 


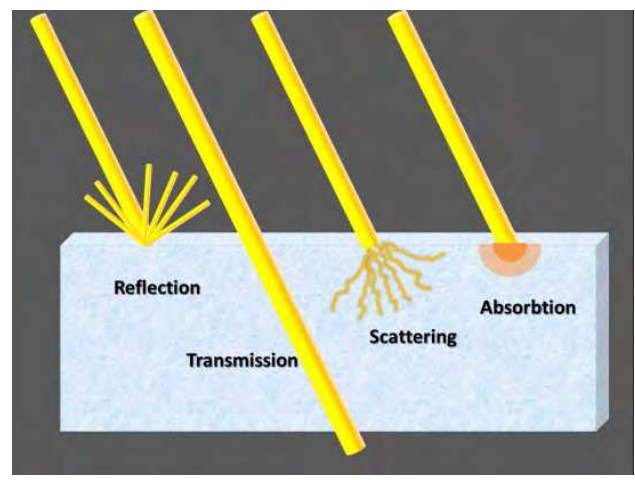

Fig. 10. Tissue interaction of laser beam.

First two types of interactions can be considered as "tissue influence on photon" is used for diagnostic sensing, imaging, and spectroscopy of tissues and biomaterials. This step of interaction aims to collect signals released from tissue of echo of sent photons. Those collected signals are processed and analyzed to evaluate the condition on tissue site or examined material or process.

\subsection{Reflection}

Some part of electromagnetic energy is reflected back by the tissue surface, which is a good example for tissue effect on laser photons. This kind of optical performance is commonly used for diagnostic or imaging studies to keep patient records. This reflected beam is read by a group of sensors and delay for reflection time is used to calculate the distance between the beam source and target point to scan surface morphology (Figure 11).

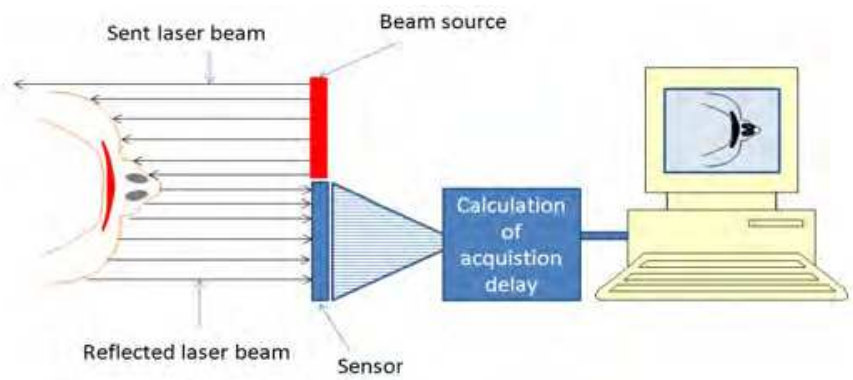

Fig. 11. Laser scanning process. Laser beam is sent to the surface to be scanned and distance between source and arget is calculated with reflection time. Computed raw data helps to reconstruct target surface topography 3 dimentionally.

3D scanning is a core application depending on used many fields of biomedical technologies. Replication of an object depends on scanning part and lasers can give an excellent alternative with high resolution in a short scanning time. Three dimensional laser scanning of macro structures of an organism, like part of (face, hand etc.) or full body [17] is helpful to lineout a topographical profile to measure or diagnose morphological abnormalities. This technique helps the clinician to compare soft tissue topography and 
landmarks before [18] and after a surgical intervention or to show the patient an estimated treatment outcome before the surgical procedure. Facial templates based on 3D laser face scans can be used to treat some face deformities by guidance of growing skeleton during childhood [19]. Laser surface scanning is also a useful tool to keep records of patients undergoing interventions at face and head.

Three dimensional digital face records obtained from laser scanning can be archived, before and after images can be compared so that success of intervention that affects the face appearance can be visualized. [20, 21] Also face images taken before the intervention can be processed to predict and show the patient end result beforehand [22]. Or image galleries can be a good source to be worked on retrospectively. Similarly dental casts of the patients can be scanned for similar reasons. Also scanned dental models can be superposed to computed tomographic or magnetic resonance imaging data to integrate facial stereophotogrammetry acquisition [23], which helps clinicians to diagnose or treatment planning. Laser scans at micro-scale can be valuable for production of dental restorations. Impressions taken from dental arch can be scanned entirely or partially with laser or ordinary light at micro-scale to produce die used preparation of dental restoration precisely [24].

Currently optoacoustic tomography systems using 2 lasers operating in the near-IR spectral range (755 and $1064 \mathrm{~nm}$ ) allow 3D imaging of individual organs and blood vessels through the entire body in animal models [25]. This novel method, in the future, would open a new era for imaging for human body.

Besides quantitative static evaluation of the body structure; laser scan systems can aid assessment of dynamic functions of externally, like recording of chest movements during breathing. However, such 4D (time dependent 3D chest position) requires a long acquisition time [26].

Laser has another point of interest in dentistry to differentiate carious tooth. This methodology depends on difference between fluorescence degree of laser beam from health and carious tooth structures [27].

\subsection{Transmission}

If target tissue is poor of light absorbing ingredient (chromofor), which is responsible to soak the photon energy and stop the beam at superficial layers of the tissue, photons are transmitted to deeper layers until all their energy is lost. Therefore, clinician should be well instrumented concerning which wavelength is absorbed by which chromofor and if the target tissue contains related chromofor or not. Based on this knowledge clinician can yield superficial or deep tissue effect intentionally or accidentally.

Depending on absorption rate of laser energy by the chromofor while travelling inside the tissue, some part of energy, gradually, can pass through all tissue layers entirely and may exit from the other side of tissue. In such cases leaving part of the beam can be used to measure some tissue ingredients via their transmission capability. With this aim the exiting part of beam can be read by a sensor to evaluate absorption rate. Therefore transmission of laser beam is a valuable feature used in diagnostic measuring. Pulse oxymeter devices read transmitted part of beam from the finger-tip and calculate percentage of oxygen 
concentration in the circulating blood. This is a useful technique to monitor vital signs of a patient closely without damaging any tissue. Similarly, working mechanism of laser doppler flow-meter depends on transmitted laser beam trough a human tooth. This device is used to test if there is a blood circulation inside the tooth pulp. According to this diagnostic value clinician decides the treatment choice.

\subsection{Scattering}

Photons are spread out their directions during their transmission to the tissue depths, when they hit any reflective structures located in the tissue. This leads change of beam direction during the travel inside the tissue. This may cause defection of effect on desired tissue depth.

\subsection{Absorption}

Photons transfer their energies to the target substance (chromofor). As a result of this action the target structure gains and transform energy, which may change its physical, chemical structure or increase the temperature. Energy absorption by chromofor occurs in 3 phases. First one is the excitation of atoms. Likewise pumping phase of lasing medium, electrons of chromofor atoms excited. As interaction at atomic level happens with gamma and X-rays, this level is out of focus for this laser chapter. Second level of tissue-radiation interaction is at molecular level, which stays within our biomedical interaction interest. Therapeutic laser applications in medical field are based on this interaction level. Such reactions excite electron bonds of biomolecules, which may break longer molecule bonds or can make changes in carbon chain [16]. On the other hand, biomolecules' oscillation can also be amplified to higher modes, which result as temperature increase macroscopically (photothermal reactions) or rotational stages can be seen in the molecules that result photochemical reactions (photodynamic therapy). Especially when therapeutic applications of laser are concerned those mentioned levels of interactions are our main effect mechanisms inside the tissue. Use of laser in clinic for therapeutic aim; targets to increase blood circulation at the lased area by heating affect and also promotes new material synthesis by the tissue cells. Regarding the therapeutically applications lasers are set at low level powersettings within certain time limits no to exceed to high photothermal reactions. Low-levellaser therapies (LLLT) are predominantly used to cure diseases by promoting tissue regeneration via photochemical activity and inducing blood circulation basically. [16]. However, as higher doses are applied or LLLT is continued over predefined time limits photothermal efficacy of laser beam becomes prominent. Continuing photon energy transfer or applying high doses associate an increase on oscillation (heat) of target molecule. At the beginning, highly oscillating molecules transfer their heat to cooler neighboring areas radially by means of conduction. This is closely depended on the tissue's thermal conductivity and diffusivity. This generated heat (photothermal effect) can be neutralized by this transfer mechanism and it's reversible. If lasing continues or higher doses are applied, tissue conduction can't suffice to transfer all the heat loaded and local temperature reaches to critical limit and cause coagulation of biomolecules that leads death (necrosis) of living cells [28]. Results of this time dependent critical temperature increase are irreversible (Figure 12). 


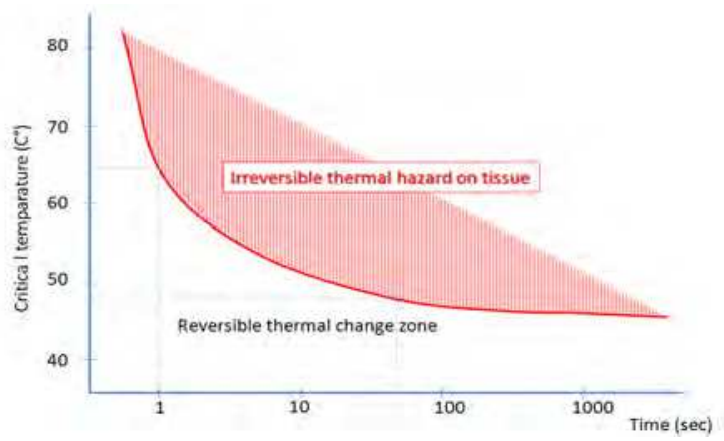

Fig. 12. Time dependent critical temperature limits lead coagulation of biomolecules and tissue necrosis. Data according to Niemz MH and Steiner R.

Further energy loading by prolonged time or with higher power doses; increase local heat until boiling level of water component. Seconds after this stage, water evaporates and the soft tissue loses its volume related with its water component ratio. Especially soft tissues, like mucosa, present a cavitation like crater on the surface of lased area. More lasing burns biomolecules, likewise proteins etc., overlaying the tissue, which causes char formation on the lased surface (Figure 13).

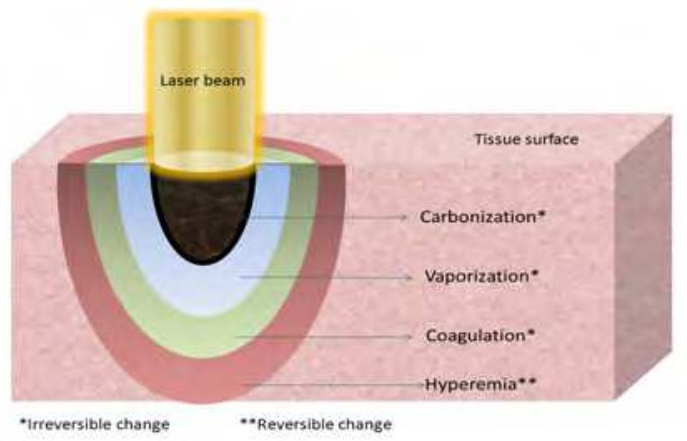

Fig. 13. Laser tissue interaction

Even though, laser tissue interaction mainly depends on the type of laser (wavelength) and also ingredients of tissue interacting with the laser beam; water is most commonly mentioned absorbent of laser in the for wavelengths longer than $1200 \mathrm{~nm}$ and shorter than $200 \mathrm{~nm}$. On the other hand, within the visible and near ultra-violet spectrum, water can be considered as transparent and transmitted through the tissue depths. Regarding the tissue composition laser beam may cause deep hazardous effect under such conditions. Therefore, for example, clinician who's going to work with a laser at wavelength between 200 to 1200 nm should know that the beam would easily penetrate deeply a tissue with high water component, like mucosa. Light absorbing organic molecules can be classified into two groups. Of the first contains amino acids and nucleus acid bases and other group the socalled chromophors. Also chromophors can be defined, mostly, as molecular structures which absorb light in the visible spectrum. Line graphic in Figure 14 summarizes atomic absorption co-efficiency over wavelengths of commonly used lasers for biomedical 
purposes. Based on this graphic clinicians determine which wavelength they should work with according to their purpose.

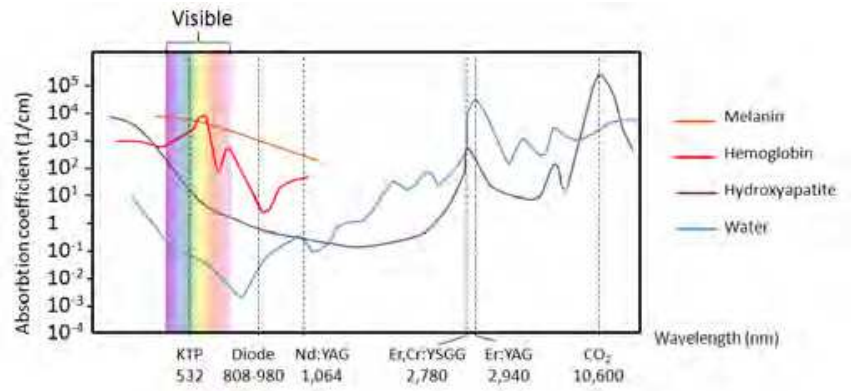

Fig. 14. Absorption spectrum of laser wavelengths.

Regarding this absorption co-efficiency graphic, erbium (Er:YAG and Er:Cr:YSGG) family and $\mathrm{CO}_{2}$ lasers had a great affinity to water and hydroxyl-apatite crystal and their photons leave their energy on HA and water. This can be an example to choose a proper wavelength to work on tissues with high HA concentration (like bone and tooth) or with high water component like mucosa. Therefore, health care professionals dealing with tooth or bone in their operational practice or researchers etc. should prefer wavelengths between 2780 to $10600 \mathrm{~nm}$ to obtain highest efficacy. On the other hand, when a high bleeding risk is expected during a soft tissue surgery, a wavelength that is highly absorbed by hemoglobin (blood) should be chosen to be able to stop bleeding.

\section{Principals to be acknowledged for dosing}

An operator, who has the obligation to work with lasers, should be equipped with basic knowledge of dosing and power-settings. It's necessary to universalize and application and its repeatability. Keeping records of those measures is a must at least to correlate the results with power-settings.

Watt $(\mathrm{W})$ is used as power unit of laser equipment. Given energy (joule-J) is calculated with multiplication of used power (W) and application time (seconds) for continuous wave modes.

$$
\text { Energy }(\text { Joule })=\text { power }(\text { Watt }) x \text { time (seconds) }
$$

However, when pulsed systems are regarded; total given energy given in a single pulse (pulse energy - J), repetition rate in a second (Hertz- Hz) and time (s) must be considered as in the following formula:

$$
\text { Energy }(\mathrm{J})=\text { pulse energy }(\mathrm{J}) \times \text { repetition rate }(\mathrm{Hz}) \times \text { time }(\mathrm{s})
$$

Energy density is termed to calculate the amount of energy delivered over a surface during laser therapy. This term defines the distribution of energy over a surface, so that a routine clinical application of the treatment method can be prescribed for all users as shown below:

$$
\text { Energy density (Fluence) }(\mathrm{J} / \mathrm{cm} 2)=\text { power }(\mathrm{W}) \times \text { time }(\mathrm{s}) / \text { area }(\mathrm{cm} 2)
$$

Clinicians should be founded of all those knowledge in order to prescribe a universal power-setting for clinical application to treat different diseases. Similarly, keeping records 
related with a treatment operation is important regarding compare healing results and power dosing. So that; in case of a postoperative complication clinician can be able to look back to the records of the operational procedure and may decide to reduce the power settings for the next patient to avoid such unintentional malpractices.

\section{Clinical applications}

Today, parallel to development of technology in health sciences, radiation has found a wide scope of use for diagnosis and imaging of many diseases and their treatment. Integration of computer and machine engineering to radiation tools spawned a new generation of radiation emission tools with higher capabilities on precise power control. Herewith, selective effectiveness of irradiation on parts of living organism is aimed in current studies. Irradiation is also X-ray, gamma radiation, infra-red, ultra-violet waves, microwaves and ultrasonic energy are also used with this purpose. Radiation energy with its wide use in biosciences has a special importance, however and in spite of such apparently wide acceptance sources for the professionals in bioengineering field is quite limited. The context of second part related with "Clinical applications" aimed to pull out and emphasize the concepts related laser energy used in medical sciences and literature review to purify knowledge for undergraduate, postgraduate biomedical engineers, health care professionals.

Laser systems have been in use in the medical sciences for diagnostic and therapeutic purposes since the 1970s. Clinical applications of laser beam can be explained with "photon influence on tissue" concept basically. Laser energy is used to modify tissue structure both in photochemical and photothermal actions. Depending on energy/power used during medical applications, lasers can be classified into 2 types: high power applications and lowlevel-laser therapy (LLLT).

\subsection{Surgery}

\subsubsection{Soft tissue cutting (incision)}

High power lasers can cut like a knife or ablate (remove large volumes) soft tissues with their photothermal effects. With this respect almost all surgical branches benefit the advantages of laser tool. Most prominent practical applications of lasers are in surgical field due to their heat production capability. Thermal damage capability of beam at desired focus diameter enables high power lasers a preferable surgical tool to cut the tissue precisely at smaller spot-sizes [29]. Especially, when incision on mucosa (rich of water component) is considered erbium family lasers would be more advantageous over other wavelengths due to high specificity to water molecule and low collateral thermal effect [30].

Surgical procedures in ophthalmology necessitate high precision for incision or disruption of transparent tissue at a certain depth. It's been presented that femtosecond lasers with low thermal collateral effect and 1.5 microm spot-size can achieve subsurface scleral photodisruption can be achieved in vitro for a variety of intrascleral incisions [31]. Moreover, when precision of incision geometry and depth on a curved eye surface is considered computer guided laser beam with minimal spot size can provide prestigious advancement on surgical practice [32]. 
Laser cutting of delicate soft tissues has also another focus on laser-assisted microdissection, which will be discussed under research section in this chapter.

\subsubsection{Tissue ablation (vaporization)}

Surgical procedures targeting removal of a pathologic tissues extending on large tissue surfaces of occupying large tissue volumes, especially with bleeding tendency, can safely be removed with laser ablation quickly $[33,34,35,36]$. Depending on wavelength selection laser can help the operator to ablate tissue superficially without damaging underlying biomaterial, likewise dental implant exposure lying beneath the oral mucosa (Figure 15).

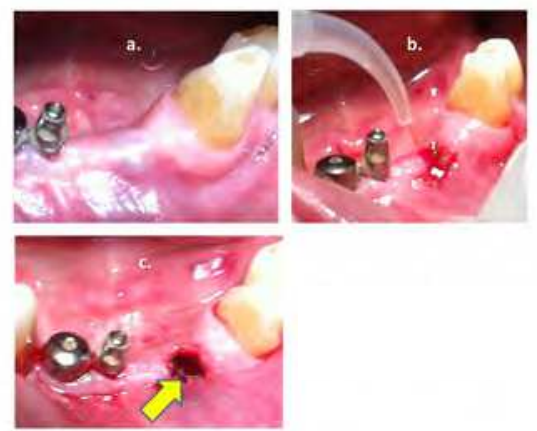

Fig. 15. Tissue ablation with Nd:YAG laser. a. Oral mucosa covering dental implant, b. Mucosa ablation, c. Exposed dental implant (arrow)

Tissue ablation with laser beam is an advantageous technique especially for removal of lesions operated endoscopically and can also provide less bleeding [37]. Owing that the beam focusing ability lasers can compromise application scope like making incision at a small size spot or tissue ablation at larger spot sizes (Figure 16).
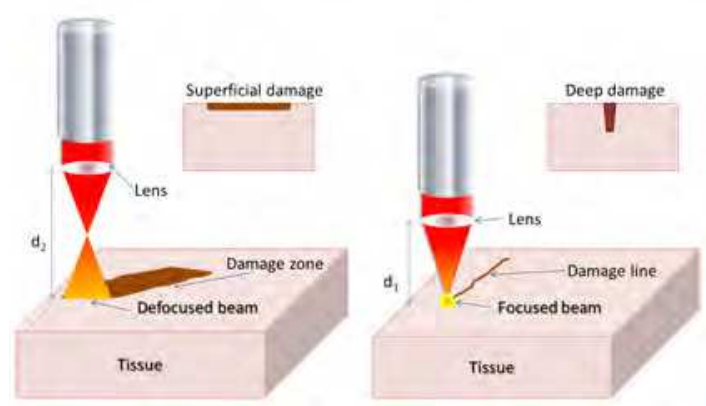

Fig. 16. Focusing and defocusing. Laser beam creates deeper impact at a narrow diameter at surface when focused. If defocused, damage depth is more superficial but damage area on the surface is wider. To defocus the beam $\mathrm{d}_{1}<\mathrm{d}_{2}$.

Additionally, collateral thermal damage potential of laser ablation technique also widens safety of the operational procedure by killing cells neighboring vaporization center. So that 
any remnants of malignant tumor cells, if present within the thermal necrosis zone, are killed and any recurrence risk is minimized [38]. Antitumoral action of laser energy can also be achieved photochemichal reactions. This concept will be mentioned within photodynamic therapy section at following context. Like tumor resection in all surgical branches, laser energy has been attributed within the extent of ophthalmology for phacoemulsification of eye lens to be replaced with an artificial one [39].

Among other surgical applications selective and precise tissue ablation is required in ophthalmology. Besides lesion or excessive tissue removals [40]; automated tissue ablations at micron-scale are also very common to modify refractive index of transparent part of eye to correct some visual deficiencies like myopia, hyperopia, and astigmatism [41].

Similarly, dermatology and plastic and reconstructive surgery clinicians take the advantage of laser ablation for removal of several lesions appearing on skin [42]. With cosmetic purposes scar tissues, tattoos and skin discolorations are also removed with lasers. When pigmented lesions are the target to be destroyed with photoablation, laser systems with wavelengths lower than $1064 \mathrm{~nm}$ are preferred due to their absorption spectrum by pigmented materials. In the present application protocols lasers present successful results and therefore are inevitable for the cosmetic procedures like hair removal and acne treatments. Photothermal and photochemical efficiencies take action simultaneously with these clinical purposes and result least thermal collateral damage on surrounding tissues. Thermal injuries of tissues, especially the skin, would easily cause scarring which leads contraction following tissue healing. In an esthetic point of view tissue contraction is an outcome that can be interpreted with 2 controversial effects. It can be regarded as a negative outcome that may lead uncontrolled scarring with unpleasant esthetic appearance for the patient at first sight. However; on contrary, if laser irradiation procedure can be fulfilled precisely on the skin, the tissue contraction can be an advantageous application to tighten up loosened aging skin [43].

\subsubsection{Blood coagulation (hemostasis)}

Besides cutting laser with wavelength can easily coagulate the blood and be able to stop blooding simultaneously [44]. That gives a clear vision for the operator especially in body regions like oral cavity (Figure17) with high bleeding tendency.

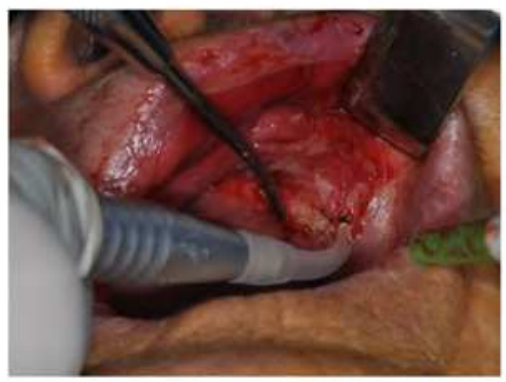

Fig. 17. Use of Nd:YAG laser to stop bleeding with its phothermal efficiency during intraoral soft tissue surgery. 
This shortens the operational time for the surgeon, lead less edema and relapse risk [36, 45] and provides a clear vision during the operation. Laser can also be a surgical tool for coagulation solely in association with scalpel surgery. This method is identified as "Laser assisted surgery" concept that can be adapted to almost all surgery disciplines using laser. When vascular pathologies of organ systems are considered, laser system with high coagulation effect can easily help the surgeon to remove vascular pathologies with lifethreatening bleeding risk more safely, due to its blood-stopping effect [46-51]. This feature of laser beam makes it a superior tool to scalpel when removal of lesions with high bleeding tendency [52] or surgical approaches of patients receiving anticoagulant therapy [53] or bleeding tendencies [54] are considered.

Lasers carried with fiber optic systems are compatible with endoscopic surgical applications where the surgeon can operate the field with via fiber optic visualization systems. Deep organ systems, like gastrointestinal tract, respiratory system (nose, sinuses, throat, lungs etc.), urinary tract, abdomen, central and peripheral nerve systems, joints and canals of glands can be operated with small entry holes on the skin. Fiber systems can carry laser beam to the target through narrow entry holes without damaging surrounding healthy tissues. Similarly intraocular bleeding, which may cause blindness very easily can be stopped with laser coagulation without touching any tissue [55].

\subsubsection{Bone surgery}

Though laser has been a focus of many experiments on living organisms since the beginning [56], its potential for bone cutting has been pointed out during 1975 [57]. Since beginning of 1980 's, following development of $\mathrm{CO}_{2}$ [58] and erbium family lasers [59], researchers have widened operational scope of laser systems for bone removal. Even though; erbium lasers looks like similar bone removal capacity as with mechanical instruments, bone healing following removal procedure is still controversial due to collateral heat production with laser beam $[60,61]$.

\subsection{Photodynamic therapy}

Photodynamic therapy (PDT) is a technique to sensitize target cells or microorganisms to light source and destroy them more efficiently with photochemical reaction based on photon energy transfer and conversion. Extrinsic dye material (photosensitizer) and intrensic molecule (oxygen) act as mediators to facilitate the transformation of molecular oxygen from triplet to singlet units via photon energy. Singlet oxygen is highly toxic to the living organisms and destroys the pathologic (tumor) cells, or microorganisms with laser at lower power settings. Although the first article appeared in 1956 [62], it was discovered more than 100 years ago by observing the killing of microorganisms when non-toxic dye (photosensitizing agent) and visible light were combined in vitro. Afterwards, it has become popular technique, due to its low systemic toxicity rate and precise application manner as a treatment for cancer, ophthalmologic disorders and in dermatology. Recently, interest on antimicrobial PDT has evolved and become a focus, due to antibiotic resistance and issues with distribution of antimicrobial drug. It has been indicated as a therapy for a large variety of local infections. Advantages of PDT include equal killing effectiveness regardless of antibiotic resistance, and a lack of induction of PDT resistance. It should be considered that antimicrobial effect would diminish when the 
light is turned-off. However, on the other hand less than perfect selectivity to microorganisms is a remarkable advantage of antimicrobial PDT. Several dye materials are used to sensitize the microorganisms via light activation. Even use of hemoglobin (blood) as a dye material with antimicrobial PDT over some oral microflora pathogens, like bacteria and fungus, in vivo has been shown to be effective [63]. PDT has been successfully used to kill pathogens and even to save life in several animal models of localized infections such as surface wounds, burns, oral sites, abscesses and the middle ear. A large number of clinical studies of PDT for viral papillomatosis lesions and for acne refer to its antimicrobial effect, but how important this antimicrobial efficacy is unclear for overall therapeutic outcome. Antimicrobial-PDT for periodontitis is a rapidly growing clinical application and other dental applications are under investigation. PDT is being clinically studied for other dermatological infections such as leishmaniasis and mycobacteria. Owing that the rise of antibiotic resistance; antimicrobial PDT applications looks like to have promising future. Advancement on bio-nanotechnology (NT) indicate innovative application spectrum in bioscience. Especially recent researches present similarities in clinical design and mechanistics. NT offers the ability to miniaturize the light source and optimization, enhancing targeting and intensity of the photodynamic reaction as well as a far greater insight into dosimetry and mechanisms of action [64, 65].

\subsection{Tissue welding}

In surgical branches wound closure has a specific significance, which is directly affect results of wound healing after the intervention. Moreover; some specific fields may require water or air tightness besides simple closure. Conventionally, tissue closure is carried out with simple sutures (stiches), however simple suturing cannot fulfill $100 \%$ secure air- or water tightness. Therefore photocoagulation of laser energy had been pointed out as an alternative and superior method for cases where wound sealing is required. Depending on the laser light sources used photothermal effect has another application in surgical practice like adhesion of two soft tissue parts. This is conventional technique to close surgical wound sites without sutures (stiches) based on coagulation of an organic soldering material, which adheres two parts of tissue and hold them together until the tissue heals [66] even in cornea closure [67]. Tissue welding method can bring an innovative ease for the procedures where suturing difficulties are faced, especially in endoscopic interventions [68]. This is a promising technique for blood vessel [69] and nerve bundle [70] anastomosis. Watertightness of tissue closure has a specific importance for the cardiovascular surgery, but also for neurosurgical procedures. Therefore; laser tissue welding has been studied and results showed that its able to repair cerebro-spinal fluid leaks [71]. Most studies present results with enhanced tissue healing with laser tissue welding, most probably due to its collateral therapeutic effect, series besides anastomosis capability. Besides albumin [72, 73], synthetic polymers are also shown as the source of soldering materials for tissue welding. $\mathrm{CO}_{2}$ [74] and diode-980 and $1064 \mathrm{~nm}$ [75] lasers are most commonly studied systems with successful tissue welding results.

\subsection{Therapeutic radiation}

Use of laser radiation is not limited to only with destructive applications in medical field. It has been demonstrated that laser energy at low doses has a positive effect on tissue 
regeneration by increased biomolecule synthesis, formation of connective tissue and increased blood circulation via generation of new vessels [76]. By the way it stimulates tissue healing while helping resolution of inflammation and pain [16]. Basically, photon energy is converted to some important biomolecules like protein, collagen, DNA and/or ATP via chemical reactions and can help to modify cell metabolism. That mechanism can amplify cell replication capability that leads regeneration. Almost all kind of tissue cells can be stimulated for reproduction. Damages due to trauma, infection, etc. can cause tissue loss that can be repaired by low-level-laser therapy (LLLT). Following any injury inflammatory chemical mediators are released by the organism, which cause pain and edema (swelling) $[77,78]$.

\subsection{Dentistry}

Besides use of laser energy for soft tissue removal or hemostasis (blood stopping) for oral surgical purposes, it found a wide range of clinical and laboratory application spectrum in field of dental medicine. When the term of "Dentistry" is uttered, first memory reminded is painful drilling with noisy and vibrating rotary tools. However, by the evolution for laser technology hard tissue removal has become more comfortable for the patients. Regarding wavelength absorption graphic in figure 14 erbium lasers have highest absorption rate by water and flowingly by HA. That makes erbium lasers most suitable spectrum for ablation of hard tissues like enamel and dentin without thermal damage (Figure 18).

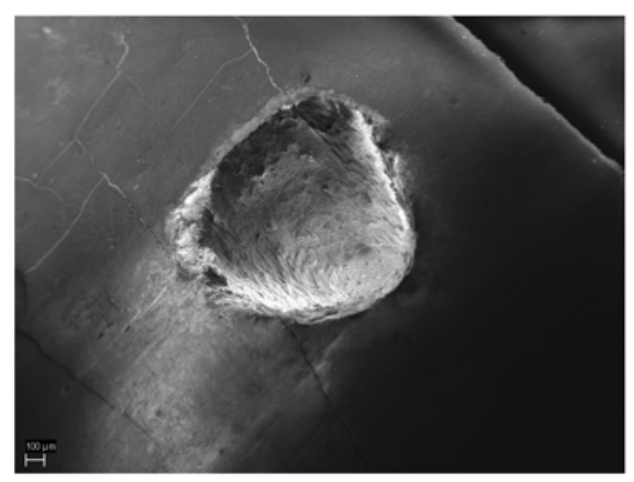

Fig. 18. Scanning electron microscopy shows smooth crater formation on tooth enamel with Nd:YAG laser ablation. (Courtesy of A. Binnaz Hazar Yoruc.)

Non-thermal ablation capability of erbium has made it a novel technology for dental applications like drilling of enamel and dentin [79]. Hard tissue removal with conventional techniques, like rotary instrumentation, looks more faster than ablation with laser; loss of vibration sense and selective ablation make laser more preferable tool than mechanic systems especially in dental procedures when removal of old fillings are considered [80]. Moreover, laser assisted cavity preparation is also advantageous when composite filling materials, which necessitate advanced roughness of the prepared surface, will be utilized [81]. Removal of dentin with laser transmitted via a fiber optic cable helps the dental clinicians for root canal preparation, where antibacterial efficiency is also required [82]. 
However, low heat production risk of erbium makes it superior regarding thermal necrosis of the living tissues like dental pulp [83] and bone marrow [84].

On the other hand, photothermal efficiency of laser beam is required in some cases like hypersensitivity of dentin [85]. The term of dentin hypersensitivity is used in cases where dentin tissue is exposed external environment due to several reasons and nerve fibers of dental pulp are stimulated by external factors like cold or acidic substances. Laser beam acts on the superficial dentin layer and melt it with its photothermal effect. This melted dentin seals open dentine tubules and blocks communication between exterior and interior environments of a tooth. This obliteration hinders entry of irritants into the dental pulp and overcomes hypersensitivity issue.

When antimicrobial PDT is considered may be dental medicine is the field that most frequently benefits from its advantageous features. Comparing other parts of the body oral cavity has a quite rich microflora regarding variety and quantity of microorganisms. Therefore, oral infections are very common in our mouth. Besides the photothermal efficiency laser energy can kill microorganisms with its antibacterial PDT effect. Laserinduced antibacterial PDT has become a novel method to treat some specific infections were eradication of microorganisms is not possible with chemical or mechanical techniques. Dental implants placed into the jaw bones are produced with a rough surface to enhance implant-bone contact area with increased frictional forces. However, this roughened surface is a proper environment for colonization of the microorganisms, which leads infection of peri-implantar tissues (periinmplantitis). It is highly difficult to eradicate all microorganisms penetrated into the deepest level of the rough surface with chemical and mechanical methods. However, different types of wavelengths can help the clinicians to kill all the bacteria living of the implant surface [86, 87]. Results of the recent studies show that antibacterial PDT is a promising method for the treatment of perimplantitis $[88,89]$.

Similarly root canal and periodontal pockets of the teeth are the sources of bacteria colonization, which leads loss tooth. With this purpose, antibacterial effect of laser energy looks like a promising tool in management of such endodontic [90] or periodontal infections [91] to provide at least decrease number of pathogenic bacteria in the periodontal pocket or root canals. However, when a periodontal pocket is considered, complete total eradication of microorganism (sterilization) cannot be possible due to irradiated pocket area cannot be isolated from the mouth entirely. Therefore, a disinfection process can be uttered rather than sterilization. Even though reduction of pathogenic bacteria account at the inflammation site co-works with our defense system and help to resolve the local infection.

Several reasons may cause discoloration of teeth that can be attributed as a bad esthetic appearance for some patients. In order to manage this discoloration chemical bleaching of teeth have been a focus of cosmetic dentistry since 1940's [92]. Likewise in all chemical reactions increased heat factor catalyzes the reaction. Researchers realized to benefit converting laser energy to heat and catalyze the bleaching process to shorten the operational time in the office. Therefore, laser systems have become popular in the dental clinics owing that energy transformation to heat induces chemical reaction of hydrogen peroxide during whitening procedure with less regression $[93,94]$. 


\section{Laser as a research tool}

\subsection{Laser spectroscopy}

Spectroscopy is an outstanding analytical method, which contributes to present state of atomic and molecular bioscience. This technique uses vibrational, rotational and other low frequency echos in a sample material. It relies on inelastic (Raman) scattering of monochromatic light, mostly a laser beam in the visible, near infrared, or near ultraviolet range. This is a sample for tissue influence on laser photons. The laser interacts with molecular vibrations, photons or other excitation in the system, resulting in an increase or decrease the energy of laser photons. The shift energy provides information about the photon modes in the system. Two of 3 dimensional analysis of any given material even at micro, or nanoscale can be fulfilled with this method [95]. Therefore lasers spectroscopy is an indispensable tool for researchers working all materials science. As a research tool with its high and analytical capability spectroscopy has been used in many fields of bioengineering and medical sciences [96-98].

\subsection{Confocal laser scanning microscopy (CLSM)}

CLSM can provide high-resolution optical images at determined tissue depth selectivity. Depending on the laser source and application modes diagnostic data can be yielded via optical information of ultra-high resolution even in deep organ systems via ultra-thin endoscopic probes, which makes confocal laser microscopy inevitable for the physicians who are responsible to diagnose any kind of malignant tumor [99]. So that tissue discrimination and manifold types of fluorescence detection can be achieved. Moreover, optical features would explore 3-D capability of tissues and enhanced recognition of tissue type and pathological status inside the living human body [100]. Early diagnosis of malignant tumors via endoscopy helps the clinicians to save many lives.

It is also called as optical sectioning. CLSM images can be yielded layer by layer from deeper levels of tissue to the surface and the data can be reconstructed by a computer to obtain three dimensional topographic appearance of tissue. This can also be a very valuable data for microbiology studies [101].

\section{Bioindustry}

Likewise in all industrial branches, use of laser technology brought novel advancements occurred in bioindustry as well. Laser systems have taken place in production of complicated or tiny objects with high precision and speed. With this respect laser technology has a special importance both in fabrication and modification of production cascade and repair processes. With material processing regard, increasing demand can be seen in the market for laser systems due to non-contact processing, reduced need for finishing operations, decreased processing cost, high productivity, improved product quality, automation worthiness, greater material utilization and minimum heat affected zone [102]. In biomedical perspective; laser systems adapted to production or repair processes have widen applicability scope and speed with advanced precision and safety. Owing that; production, modification, and assembling can be attributed as the major courses of laser applications in bioindustry. 


\subsection{Laser - Matter interaction}

Regardless the type of procedure, which is being processed; laser-matter interaction, likewise as between laser and tissue should be knowledge. In order not to exceed limits to manufacturing technologies and keep the context as predetermined, rather giving detailed opto-electric physics; briefly the laser-matter interaction can be defined as the same in tissue-laser interaction. In addition to photothermal, photochemical and photomechanic effects laser energy may have photomagnetic effect on materials [25]. Similarly, the interaction is closely related with wavelength - matter reflectivity relation, produced temperature, present surface films, angle of incidence and surface roughness, besides laser beam (power settings, time, shot intervals, focusing, etc.) and matter properties. Laser processing used to be most predominantly preferred in metal processing, however synthetic material processing in bioindustry is also developing with a great acceleration recently, especially in rapid prototyping.

Laser photon impacting the substance surface may or may not change its phase/state. With this regard; phase/state changes can occur in 3 ways:

1. Solids undergo vaporization:

a. Machining (Drilling, cutting, surface roughening, engraving, scribing, marking etc.)

b. Coating - deposition (Ceramic coating on metal etc.)

c. Laser assisted purification

d. Laser spectroscopy

2. Solids undergo liquid
a. Adhering (Welding - brazing)
b. Reclamation
c. Surface alloying - cladding
d. Manufacturing (Rapid prototyping - sintering)

3. Liquids undergo solid

a. Rapid prototyping

On the other hand no phase changes help to modify a solid matter to a desired status as follows:
a. Surface hardening
b. Shocking - shot peening
c. Forming (Bending or straightening)
d. Semiconductor annealing

\subsection{Sintering}

Laser sintering (LS) has been a focus of bioengineering interest since early 1990's [103]. Basically, a focused laser beam moving on a material (metal, ceramic or polymer) powder surface melts and fuses the powder at a desired shape layer-by-layer. Comparing to conventional casting techniques porosity of the product can be altered as desired with LS. Development of computer technology both in hard- and software contributed to an astounding growth of laser systems. "Three-dimensional" modeling technique adapted to computer guided finely focused laser beam now allows design and production of any object 
at micro scale. Especially modeling and rapid prototyping concepts have developed within each other based on sintering from a laser perspective. These synergetic developmental changes expand application scope and speed of laser in bioindustry. Rapid fabrication (prototyping) of prosthesis or scaffold [104] with LS before the surgery has 2 major advantages for the surgeon and the patient. First thing first, operator has the ability to work on this study model before the surgery and is capable to prepare any kind of framework or a template, even in complex 3D architecture, to be used as a fixation or stabilization material etc. $[105,106]$. On contrary, these time consuming preparation or adaptation steps of the operational procedure should be fulfilled precisely during surgery when tissues are opened and the clock is tick tacking. Secondly, the operator would be familiar with the scene that he/she is going to face during surgery and can prepare and surgical template, which provides a $100 \%$ precise bone drilling or cutting capability as planned previously [107].

Those 2 important developments on LS prototyping can be attributed as innovative features that rise success rates of many surgical procedures in maxillofacial surgery, orthopedics [108], neurosurgery [109]. Also bony defects to be repaired with a bone graft replacement can be imagined initially with computed tomography. Advanced softwares enable the operator to visualize and measure the defect area and create a suitable 3D prosthesis to fit defect site perfectly and work as a graft material for replacement. Created 3D model in the digital environment (mostly prepared as a *.stl file) can be transferred to a rapid prototyping laser machine to materialize solid graft material. Related with features of prototyping method computer guided laser beam produce the design from solid materials, powder or liquid feeds. Manufactured bone scaffolds made of osteoconductive materials can serve as a tray for cell cultures with bioengineering applications [110]. LS metals products, like dental crowns, provide superior bonding to ceramic, as the bonding capability is closely related with chemical structure on the metal surface rather than porosity value [111].

\subsection{Machining}

Laser technology has brought a fresh breath to manufacturing of metal instruments, prosthesis of fixation devices etc. requiring precise cutting, drilling, engraving, labeling or marking. Conventional techniques using mechanical removal of matter result thermal or physical damage of the processed material that may disrupt its biologic performance. In such cases high power lasers, especially with femto- or picosecond shots, can offer an excellent procedure with minimal deformation and chemical damage on the processed material.

\subsubsection{Drilling, cutting}

Under machining concept material processing drilling and cutting procedures is the two most common ones covered. With this respect highest precision is obtained for drilling, cutting etc. procedures with minimum crust and wastage, or no foreign body remnants [112], which do affect tissue reaction to the product if it's going to be placed into a living body. With this regard ultra-short laser pulses have a wide application scope in production of metals, ceramics and organic materials with enhanced precision with minimal hazard even on highly fragile materials like glass [113]. 


\subsubsection{Surface modification}

Final stages of bioindustrial production process may necessitate surface modification of a material at the end for several purposes like labeling, marking, coloring, engraving a specific surface topography (microstructuring), surface hardening and coating the material with another substance for environmental tissue adaptation or at least for marketing. Moreover, laser ablation has been shown as a useful technique to strip (clean-up) a thin layer from the surface of a metal for preparatory processes for further surface modification.

\subsection{Microtexturing}

In last 3 decades bioindustry has shown a growing interest in microtexturing (structuring) of implant surfaces to improve their physical and biologic characteristics. Amount of contact area between bone tissue and implant surface is highly important for the stability, which can be attributed as the health and survival of implant. Therefore, in such cases surface roughness is increased to gain maximum frictional forces in between. Conventional chemical (acid etching) and mechanical (sand blasting) erosive techniques leaves unintentionally foreign contaminants on the implant surface that may cause rejection of implant by the tissue following an adverse tissue reaction. With this perspective, clean surface roughening even at micro scale at a predetermined surface topography can be available with laser systems (Nd:YAG, $\mathrm{CO}_{2}$, and excimer) with no foreign substance contamination. Use of ultra-short pulses is indicated as a cost-efficient method manufacturing of bio-friendly medical implant surfaces. [114] Nowadays, researches are concentrated on nano-roughness concept instead of microtexturing $[115,116]$ due to this nano-roughness can present more attractive physical topography for attachment of different cell types selectively [117]. That laser induced biotechnology would bring the option to modify the implant surface selectively depending on the environment to be faced, like to be an attractive surface for tissue cells, while surface structure can be changed to protect microorganism adhesions.

\subsection{Surface coating/cladding - Alloying}

Coating a surface has plenty of additive effects for biomaterials like improving biocompatibility or corrosion resistance, surface roughness and chemical bonding capability, therefore is a frequently subjected to many research studies [118]. Laser coating looks like a promising method especially for composite material coatings even at ultra-thin layers on biomaterials that would face complex tissue interactions selectively in bioengineering applications [119]. Under this title; alloying with other metals likewise coating (cladding) with different substances can be uttered, however surface alloying can offer superior corrosion and wear protective coating nature when compared with ceramic coatings.

\subsection{Surface heat treatment - Hardening}

Photothermal effect of laser helps to treat surface of materials with heat, which helps hardening on metals. This treatment modality used to manage wear reduction; however it has currently found a place in production technologies to change metallurgical and mechanical properties as well. Hardness, fatigue time and strength of metals can be augmented while wear and friction features are reduced with laser heat treatment, if needed selectively. 


\subsection{Coloring, labeling/marking}

Like surface hardening procedures, laser energy can modify metal surfaces' composition and change its color. Many industrial manufacturers practice this technique for classification or marking their products. Color coding is a user friendly technique preferred by manufacturers that help management or classification of hand instruments or drills. Similarly, simple marks showing length printed with lasers on gauges or drills (Figure 19) provides a striking ease for the users to avoid complications during surgery.

Fig. 19. Surface modification with laser on drill for labeling and marking (Courtesy of Bicon Co.)

\subsection{Welding}

In contrast to conventional welding techniques laser welding makes it possible to assemble two metallic pieces with/without a soldering material remotely and can provide highest heat source intensity on a very small spot size [25]. Therefore, its joining efficiency can be attributed to be higher than other welding systems. Though high costs, this technique can be automatized at atmospheric conditions with high precision with very short on/off timing and cause minimal or no contamination and collateral damage. Materials like magnetic metals of heat sensitive substances can be welded without any damage and shrinkage. Therefore, besides manufacturing of instruments laser welding has been used dental laboratories to joind dental prosthesis parts on standard master models [121]. Excimer, $\mathrm{Nd}$ :YAG and carbonmonoxide lasers are more advantageous due to the shorter wavelength natures over the $\mathrm{CO}_{2}$ laser. Highly focused beam profile minimizes collateral thermal increase in neighboring areas or tissues [122]. Specially designed laser tips (Figure 20) contribute to focus condense the beam in a small spot widens safety limits and opens a new area for laser welding to be performed inside the living organism, like metal welding in mouth [123].

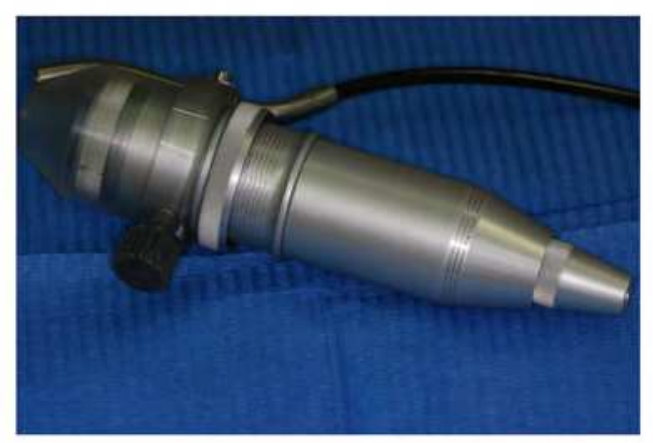

Fig. 20. Specially designed Nd: YAG laser tip for intraoral metal welding. (Courtesy of Prof. Carlo Forniani) 


\section{Laser safety}

Lasers can potentially damage any part of our body unintentionally. Range of those accidents is quite wide, between increased local blood flow at the target area (hyperemia) to death. Therefore; regardless the reason use of laser necessitates some strict safety regulations. Such regulations are issued by local authorities and owner of the laser system has the primary responsibility to operate the system according to those regulations. International standards like ANSI 136.1, 3, 4, 5, 6, 7 and IEC 60825 define classification of lasers according to their hazardous risks and operational powers. Moreover; additional local regulations, if present, should also be obeyed by the personnel dealing with laser operation. First step of these laser safety precautions is training of professionals, who are going to work in an operation environment where a laser works. Regardless their acts in the operation room all personnel should have this basic training. People who are going to operate with laser or laser technicians or laser safety operators responsible from maintenance and management of laser should take advance training [124].

Concerning the damage risk and power of lasers those systems classify lasers Class $1,1 \mathrm{M}, 2$, $2 \mathrm{M}, 3 \mathrm{R}, 3 \mathrm{~B}, 4$. Class $3 \mathrm{~B}$ and 4 are defined as hazardous for eyes respectively. Therefore, safety precautions are at the highest level when other classes are regarded. When eye safety is regarded; wearing goggles with wavelength specific filter is a must within the operation room. Protective precautions like automatic door lock installation at the operation room, isolating untargeted areas, placing warning signs outside the door and "laser safety training" etc are inevitable. Class 3B and 4 class lasers are commonly used for medical purposes for tissue removal or modification, making a cut (incision), eradicating bacteria, killing tumor cells, etc., or biomedical research, or in bioindustry. Clinicians operate laser must have "Laser Safety Training for Healthcare Professionals" certificate. However, health care professionals working in laser operation site have the obligation to get orientation training at least.

\section{Acknowledgement}

Author would like to acknowledge Prof. Carlo Forniani, Assoc. Prof. A. Binnaz Hazar Yoruc and Bicon Co. for sharing their image data with courtesy.

\section{References}

[1] Licht SH (1983) Therapeutic Electricity and Ultraviolet Radiation. Baltimore: Williams \& Wilkins.

[2] Ford A, Morris SM, Coles HJ (2006) Photonics and lasing in liquid crystals. Materials Today 9(7-8): 36-42.

[3] Shimomura O, Johnson F H, Saiga Y (1962) Extraction, purification and properties of aequorin, a bioluminescent protein from luminous hydromedusan, Aequorea J Cell Comp Physiol (59): 223-239.

[4] Shaner NC, Steinbach PA, Tsien RY. (2005). A guide to choosing fluorescent proteins. Nature Methods. 2: 905-909.

[5] Giepmans BNG, Adams SR, Ellisman MH, Tsien RY (2006) Review-the fluorescent toolbox for assessing protein location and function. Science 312: 217-224.

[6] Gather MC, Yun SH (2011) Single-cell biological lasers. Nature Photonics. 5: 406-410. 
[7] Shen Z, Burrows PE, Bulović V, Forrest SR, Thompson ME (27 June 1997) Three-Color, Tunable, Organic Light-Emitting Devices. Science. 276(5321): 2009-2011.

[8] De Young R J, Weaver WR (August 18, 1986) Low-threshold solar-pumped laser using C2F5I. Applied Physics Letters. 49(7): 369-370.

[9] Siegman AE (Nov/Dec 2000) Laser Beams and Resonators: Beyond the 1960s. IEEE J. 6(6): $1389-1399$.

[10] Rabien A. (2010) Laser Microdissection. Methods in Molecular Biology. 576: 39-47.

[11] Gu L, Mohanty SK (2011 Dec) Targeted microinjection into cells and retina using optoporation. J Biomed Opt. 16(12): 128003.

[12] Amini-Nik S, Kraemer D, Cowan ML, Gunaratne K, Nadesan P, Alman BA, Miller RJ (2010 Sep 28) Ultrafast mid-IR laser scalpel: protein signals of the fundamental limits to minimally invasive surgery. PLoS One. 5(9)pii: e13053.

[13] Amini-Nik S, Kraemer D, Cowan ML, Gunaratne K, Nadesan P, Alman BA, Miller RJ. (2010 Sep 28) Ultrafast mid-IR laser scalpel: protein signals of the fundamental limits to minimally invasive surgery. PLoS One. 5(9). pii: e13053.

[14] Wong YT, Finley CC, Giallo JF 2nd, Buckmire RA (2011 Aug) Novel CO2 laser robotic controller outperforms experienced laser operators in tasks of accuracy and performance repeatability. Laryngoscope.121(8):1738-42.

[15] Mattos LS, Caldwell DG, Dellepiane M, Grant E (2010) Design and control of a robotic system for assistive laser phonomicrosurgery. Conf Proc IEEE Eng Med Biol Soc. 2010: 5411-5.

[16] Baxter GD (April 4, 1994) Therapeutic Lasers: Theory and Practice. Edinburgh: Churchill Livingstone.

[17] Bretschneider T, Koop U, Schreiner V, Wenck H, Jaspers S (2009 Aug) Validation of the body scanner as a measuring tool for a rapid quantification of body shape. Skin Res Technol. 15(3):364-9.

[18] Toma AM, Zhurov A, Playle R, Ong E, Richmond S (2009 Feb) Reproducibility of facial soft tissue landmarks on 3D laser-scanned facial images. Orthod Craniofac Res. 12(1):33-42.

[19] Kau CH, Zhurov A, Richmond S, Cronin A, Savio C, Mallorie C (2006 Feb) Facial templates: a new perspective in three dimensions. Orthod Craniofac Res.9(1):10-7.

[20] Shim WH, Yoon SH, Park JH, Choi YC, Kim ST (2010 Dec) Effect of botulinum toxin type A injection on lower facial contouring evaluated using a three-dimensional laser scan. Dermatol Surg. 36(4): 2161-6.

[21] Shimomatsu K, Nozoe E, Ishihata K, Okawachi T, Nakamura N (2012)Threedimensional analyses of facial soft tissue configuration of Japanese females with jaw deformity - A trial of polygonal view of facial soft tissue deformity in orthognathic patients. J Craniomaxillofac Surg. 2011 Nov 9. [Epub ahead of print]

[22] Plooij JM, Maal TJ, Haers P, Borstlap WA, Kuijpers-Jagtman AM, Bergé SJ (2011 Apr) Digital three-dimensional image fusion processes for planning and evaluating orthodontics and orthognathic surgery. A systematic review. Int J Oral Maxillofac Surg. 40(4): 341-52.

[23] Rosati R, De Menezes M, Rossetti A, Sforza C, Ferrario VF (2010 Jul) Digital dental cast placement in 3-dimensional, full-face reconstruction: a technical evaluation. Am J Orthod Dentofacial Orthop. 138(1): 84-8. 
[24] Chan DC, Chung AK, Haines J, Yau EH, Kuo CC (2011 Sep-Oct) The accuracy of optical scanning: influence of convergence and die preparation. Oper Dent. 36(5): 486-91.

[25] Brecht HP, Su R, Fronheiser M, Ermilov SA, Conjusteau A, Oraevsky AA (2009 NovDec) . Whole-body three-dimensional optoacoustic tomography system for small animals. J Biomed Opt. 14(6): 064007.

[26] Catanuto G, Patete P, Spano A, Pennati A, Baroni G, Nava MB (2009 Nov-Dec) New technologies for the assessment of breast surgical outcomes. Aesthet Surg J. 29(6): 505-8.

[27] Rando-Meirelles MP, de Sousa Mda L (2011 Mar) Using laser fluorescence (DIAGNOdent) in surveys for the detection of noncavitated occlusal dentine caries. Community Dent Health. 28(1): 17-21.

[28] Markolf HN. (2011) Laser-Tissue Interactions: Fundamentals and Applications In: Raulin C, Karsai S, editors. Springer, Kunzi-Rapp K. and Steiner R., Intense Pulsed Light Technology, Laser and IPL Technology in Dermatology and Aesthetic Medicine. Berlin Heidelberg: Springer-Verlag. pp. 37 - 40.

[29] Xia SJ (2009 May)Two-micron (thulium) laser resection of the prostate-tangerine technique: a new method for BPH treatment. Asian J Androl. 11(3): 277-81.

[30] Ryu SW, Lee SH, Yoon HJ (2011) A comparative histological and immunohistochemical study of wound healing following incision with a scalpel, $\mathrm{CO}(2)$ laser or Er,Cr:YSGG laser in the Guinea pig oral mucosa. Acta Odontol Scand. 2011 Dec 12. [Epub ahead of print]

[31] Sacks ZS, Kurtz RM, Juhasz T, Mourau GA (2002 Jul) High precision subsurface photodisruption in human sclera. J Biomed Opt. 7(3): 442-50.

[32] Nubile M, Carpineto P, Lanzini M, Calienno R, Agnifili L, Ciancaglini M, Mastropasqua L (2009 Jun) Femtosecond laser arcuate keratotomy for the correction of high astigmatism after keratoplasty. Ophthalmology. 116(6): 1083-92.

[33] Tasar F, Sener BC (2009) Laser use in Oral and Maxillofacial Surgery. In: LASERS in Dentistry: Practical Textbook. Vitale M, Caprioglio C, editors. Bologna: Edizioni Martinada, pp. 243-252.

[34] Santos NR, Aciole GT, Marchionni AM, Soares LG, dos Santos JN, Pinheiro AL (2010 Oct) A feasible procedure in dental practice: the treatment of oral dysplastic hyperkeratotic lesions of the oral cavity with the CO2 laser. Photomed Laser Surg. 28 Suppl 2: S121-6.

[35] Gao H, Ding X, Wei D, Cheng P, Su X, Liu H, Zhang T. (2011 Dec) Endoscopic management of benign tracheobronchial tumors. J Thorac Dis. 3(4): 255-61.

[36] Saccomandi P, Schena E, Di Matteo FM, Pandolfi M, Martino M, Rea R, Silvestri S (2011 Aug) Laser Interstitial Thermotherapy for pancreatic tumor ablation: Theoretical model and experimental validation. Conf Proc IEEE Eng Med Biol Soc. 2011: 55858.

[37] Virgin FW, Bleier BS, Woodworth BA (2010 Jun) Evolving materials and techniques for endoscopic sinus surgery. Otolaryngol Clin North Am. 43(3): 653-72, xi.

[38] Ishii J, Fujita K, Munemoto S, Komori T (2004 Feb) Management of oral leukoplakia by laser surgery: relation between recurrence and malignant transformation and clinicopathological features. J Clin Laser Med Surg. 22(1): 27-33.

[39] Chambless WS (1988 Mar) Neodymium:YAG laser phacofracture: an aid to phacoemulsification. J Cataract Refract Surg. 14(2): 180-1. 
[40] Lindfield D, Ansari G, Poole T (2012 Feb) Nd:YAG Laser Treatment for Epithelial Ingrowth After Laser Refractive Surgery. Ophthalmic Surg Lasers Imaging. 9: 1-3.

[41] Manche EE, Carr JD, Haw WW, Hersh PS (1998 Jul) Excimer laser refractive surgery. West J Med. 169(1): 30-8.

[42] Goldberg DJ (2008) Laser Dermatology: Pearls and Problems. Massachusetts: Blackwell. pp. 172-4.

[43] Goldman A, Wollina U, de Mundstock EC (2011 May) Evaluation of Tissue Tightening by the Subdermal Nd: YAG Laser-Assisted Liposuction Versus Liposuction Alone. J Cutan Aesthet Surg. 4(2): 122-8.

[44] Yang SS, Hsieh CH, Lee YS, Chang SJ (2012) Diode laser (980 nm) enucleation of the prostate: a promising alternative to transurethral resection of the prostate. Lasers Med Sci. 2012 Jan 27. [Epub ahead of print]

[45] Raewyn C, Paul W (2010 Jun) Management of congenital lingual dermoid cysts. Int J Pediatr Otorhinolaryngol. 74(6): 567-71.

[46] Taşar F, Tümer C, Sener BC, Sençift K (1995 Jul-Sep) Lymphangioma treatment with Nd-YAG laser. Turk J Pediatr. 37(3): 253-6.

[47] Lee JC, Kim JW, Lee YJ, Lee SR, Park CR, Jung JP (2011 Aug) Surgical management of auricular infantile hemangiomas. Korean J Thorac Cardiovasc Surg. 44(4): 311-3.

[48] Daramola OO, Chun RH, Kerschner JE (2012 Jan) A case of large bladder hemangioma successfully treated with endoscopic yttrium aluminium garnet laser irradiation. Arch Otolaryngol Head Neck Surg. 138(1): 72-5.

[49] Takemoto J, Yamazaki Y, Sakai K (2011 Dec) Treatment of Lymphangioma with CO2 Laser in the Mandibular Alveolar Mucosa. Int J Urol. 18(12): 854-6.

[50] Arslan A, Gursoy H, Cologlu S (2011 Nov) Treatment of Lymphangioma with CO2 Laser in the Mandibular Alveolar Mucosa. J Contemp Dent Pract. 12(6): 493-6.

[51] Rameau A, Zur KB (2011 Sep) KTP laser ablation of extensive tracheal hemangiomas. Int J Pediatr Otorhinolaryngol. 75(9): 1200-3.

[52] Hochman M, Adams DM, Reeves TD (2011 May-Jun) Current knowledge and management of vascular anomalies: I. Hemangiomas. Arch Facial Plast Surg. 13(3): 145-51.

[53] Chung DE, Wysock JS, Lee RK, Melamed SR, Kaplan SA, Te AE (2011 Sep) Outcomes and complications after $532 \mathrm{~nm}$ laser prostatectomy in anticoagulated patients with benign prostatic hyperplasia. J Urol. 186(3): 977-81.

[54] Green D (2007 Jun) Management of bleeding complications of hematologic malignancies. Semin Thromb Hemost. 33(4): 427-34.

[55] Gil AL, Azevedo MJ, Tomasetto GG, Muniz CH, Lavinsky J (2011 Sep-Oct) Treatment of diffuse diabetic maculopathy with intravitreal triamcinolone and laser photocoagulation: randomized clinical trial with morphological and functional evaluation. Arq Bras Oftalmol. 74(5): 343-7.

[56] Goldman L, Shumrick DA, Rockwell RJ Jr, Meyer R (1968 Mar) The laser in maxillofacial surgery. Preliminary investigative surgery.. Arch Surg. 96(3): 397-400.

[57] Verschueren RC, Koudstaal J, Oldhoff J (1975 Mar)The carbon dioxide laser; some possibilities in surgery. Acta Chir Belg. 74(2): 197-204.

[58] Gertzbein SD, deDemeter D, Cruickshank B, Kapasouri A (1981) The effect of laser osteotomy on bone healing.. Lasers Surg Med. 1(4): 361-73. 
[59] Nelson JS, Yow L, Liaw LH, Macleay L, Zavar RB, Orenstein A, Wright WH, Andrews JJ, Berns MW (1988) Ablation of bone and methacrylate by a prototype midinfrared erbium:YAG laser. Lasers Surg Med. 8(5): 494-500.

[60] Martins GL, Puricelli E, Baraldi CE, Ponzoni D (2011 Apr) Bone healing after bur and Er:YAG laser ostectomies. J Oral Maxillofac Surg. 69(4): 1214-20.

[61] Cloutier M, Girard B, Peel SA, Wilson D, Sándor GK, Clokie CM, Miller D (2010 Dec) Calvarial bone wound healing: a comparison between carbide and diamond drills, Er:YAG and Femtosecond lasers with or without BMP-7. Oral Surg Oral Med Oral Pathol Oral Radiol Endod. 110(6): 720-8.

[62] Schultz KH, Wiskemann A, Wulf K (1956) Clinical and experimental studies on photodynamic efficacy of phenothiazine derivatives with special reference to megaphen. Arch Klin Exp Dermatol. 202(3): 285-98.

[63] Meral G, Tasar F, Kocagöz S, Sener C (2003) Factors affecting the antibacterial effects of Nd:YAG laser in vivo. Lasers Surg Med. 32(3): 197-202.

[64] Allison RR, Mota HC, Bagnato VS, Sibata CH (2008 Mar) Bio-nanotechnology and photodynamic therapy--state of the art review. Photodiagnosis Photodyn Ther. 5(1): 19-28.

[65] Li WT (2009 Oct) Nanotechology-based strategies to enhance the efficacy of photodynamic therapy for cancers. Curr Drug Metab. 10(8): 851-60.

[66] Abergel RP, Lyons RF, White RA, Lask G, Matsuoka LY, Dwyer RM, Uitto J (1986 May) Skin closure by Nd:YAG laser welding 1986 May.

[67] Rasier R, Ozeren M, Artunay O, Bahçecioğlu H, Seçkin I, Kalaycoğlu H, Kurt A, Sennaroğlu A, Gülsoy M (2010 Sep) Corneal tissue welding with infrared laser irradiation after clear corneal incision. Cornea.29(9): 985-90.

[68] Bleier BS, Cohen NA, Chiu AG, O'Malley BW Jr, Doghramji L, Palmer JN (2010 MayJun) Endonasal laser tissue welding: first human experience. Am J Rhinol Allergy. 24(3): 244-6.

[69] Esposito G, Rossi F, Matteini P, Puca A, Albanese A, Sabatino G, Maira G, Pini R (2011 Apr-Jun) Present status and new perspectives in laser welding of vascular tissues. J Biol Regul Homeost Agents. 25(2): 145-52.

[70] Bloom JD, Bleier BS, Goldstein SA, Carniol PJ, Palmer JN, Cohen NA (2012 Jan) Laser facial nerve welding in a rabbit model. Arch Facial Plast Surg. 14(1): 52-8.

[71] Bleier BS, Palmer JN, Sparano AM, Cohen NA (2007 Nov) Laser-assisted cerebrospinal fluid leak repair: an animal model to test feasibility. Otolaryngol Head Neck Surg. 137(5): 810-4.

[72] Ware MH, Buckley CA (2003) The study of a light-activated albumin protein solder to bond layers of porcine small intestinal submucosa. Biomed Sci Instrum. 39: 1-5.

[73] Pabittei DR, Heger M, Beek JF, van Tuijl S, Simonet M, van der Wal AC, de Mol BA, Balm R (2011 Jan)Optimization of suture-free laser-assisted vessel repair by solderdoped electrospun poly( $\varepsilon$-caprolactone) scaffold. Ann Biomed Eng. 39(1): 223-34.

[74] Youssef TF, Ahmed MR, Kassab AN (2010) Utilization of CO(2) laser for temporal fascia graft welding in myringoplasty: an experimental study on guinea pigs. ORL J Otorhinolaryngol Relat Spec. 72(2): 119-23.

[75] Hu L, Lu Z, Wang B, Cao J, Ma X, Tian Z, Gao Z, Qin L, Wu X, Liu Y, Wang L (2011 Mar) Closure of skin incisions by laser-welding with a combination of two near- 
infrared diode lasers: preliminary study for determination of optimal parameters. J Biomed Opt. 16(3): 038001.

[76] Prabhu V, Rao SB, Chandra S, Kumar P, Rao L, Guddattu V, Satyamoorthy K, Mahato KK (2012 Feb) Spectroscopic and histological evaluation of wound healing progression following Low Level Laser Therapy (LLLT). J Biophotonics. 5(2): 16884. doi: 10.1002/jbio.201100089.

[77] Yan W, Chow R, Armati PJ (2011 Jun) Inhibitory effects of visible 650-nm and infrared 808 -nm laser irradiation on somatosensory and compound muscle action potentials in rat sciatic nerve: implications for laser-induced analgesia. J Peripher Nerv Syst. 16(2): 130-5.

[78] Marcos RL, Leal Junior EC, Messias Fde M, de Carvalho MH, Pallotta RC, Frigo L, dos Santos RA, Ramos L, Teixeira S, Bjordal JM, Lopes-Martins RÁ (2011 Nov-Dec) Infrared $(810 \mathrm{~nm})$ low-level laser therapy in rat achilles tendinitis: a consistent alternative to drugs. Photochem Photobiol. 87(6): 1447-52.

[79] Rizcalla N, Bader C, Bortolotto T, Krejci I (2012 Feb) Improving the efficiency of an Er:YAG laser on enamel and dentin. Quintessence Int. 43(2): 153-60.

[80] Chan KH, Hirasuna K, Fried D (2011 Sep) Rapid and selective removal of composite from tooth surfaces with a $9.3 \mu \mathrm{m} \mathrm{CO} 2$ laser using spectral feedback. Lasers Surg Med. 43(8): 824-32. doi: 10.1002/lsm.21111.

[81] De Moor RJ, Delme KI (2010 Apr) Laser-assisted cavity preparation and adhesion to erbium-lased tooth structure: part 2. present-day adhesion to erbium-lased tooth structure in permanent teeth. J Adhes Dent. 12(2): 91-102.

[82] Moshonov J, Sion A, Kasirer J, Rotstein I, Stabholz A (1995 Feb) Efficacy of argon laser irradiation in removing intracanal debris. Oral Surg Oral Med Oral Pathol Oral Radiol Endod. 79(2): 221-5.

[83] Kilinc E, Roshkind DM, Antonson SA, Antonson DE, Hardigan PC, Siegel SC, Thomas JW (2009 Aug) Thermal safety of Er:YAG and Er,Cr:YSGG lasers in hard tissue removal. Photomed Laser Surg. 27(4): 565-70.

[84] Stübinger S, Nuss K, Pongratz M, Price J, Sader R, Zeilhofer HF, von Rechenberg B (2010 Oct)Comparison of Er:YAG laser and piezoelectric osteotomy: An animal study in sheep. Lasers Surg Med. 42(8): 743-51.

[85] Sgolastra F, Petrucci A, Gatto R, Monaco A (2011 Mar) Effectiveness of laser in dentinal hypersensitivity treatment: a systematic review. J Endod. 37(3): 297-303.

[86] Stubinger S, Etter C, Miskiewicz M, Homann F, Saldamli B, Wieland M, Sader R (2010 Jan-Feb) Surface alterations of polished and sandblasted and acid-etched titanium implants after Er:YAG, carbon dioxide, and diode laser irradiation. Int J Oral Maxillofac Implants. 25(1): 104-11.

[87] Gonçalves F, Zanetti AL, Zanetti RV, Martelli FS, Avila-Campos MJ, Tomazinho LF, Granjeiro JM (2010 Apr) Effectiveness of 980-mm diode and 1064-nm extra-longpulse neodymium-doped yttrium aluminum garnet lasers in implant disinfection. Photomed Laser Surg. 28(2): 273-80.

[88] Cavus O (2011) Potasyum titanil fosfat laserin porfiromonas gingivalis ve osteoblastlar üzerine fotodinamik etkinliğinin incelenmesi, Ph.D. Thesis. Marmara University Institute of Health, Istanbul, Turkey. 
[89] Shibli JA, Martins MC, Theodoro LH, Lotufo RF, Garcia VG, Marcantonio EJ (2003 Mar) Lethal photosensitization in microbiological treatment of ligature-induced periimplantitis: a preliminary study in dogs. J Oral Sci. 45(1): 17-23.

[90] Peters OA, Bardsley S, Fong J, Pandher G, Divito E (2011 Jul) Disinfection of root canals with photon-initiated photoacoustic streaming. J Endod. 37(7): 1008-12.

[91] Benhamou V (2009 Apr) Photodisinfection: the future of periodontal therapy. Dent Today. 28(4): 106, 108-9.

[92] Grogan DF (1946 Mar) Agents used in bleaching teeth. Tufts Dent Outlook. 20: 20-3.

[93] Torres CR, Barcellos DC, Batista GR, Borges AB, Cassiano KV, Pucci CR (2011 May) Assessment of the effectiveness of light-emitting diode and diode laser hybrid light sources to intensify dental bleaching treatment. Acta Odontol Scand. 69(3): 176-81.

[94] Al Quran FA, Mansour Y, Al-Hyari S, Al Wahadni A, Mair (2011 Winter) Efficacy and persistence of tooth bleaching using a diode laser with three different treatment regimens. Eur J Esthet Dent. 6(4): 436-45.

[95] Demtröder W (2002) Laser Spectroscopy: basic concepts and instrumentation. Berlin: Springer-Verlag

[96] Baker R, Matousek P, Ronayne KL, Parker AW, Rogers K, Stone N. 2007 Jan) Depth profiling of calcifications in breast tissue using picosecond Kerr-gated Raman spectroscopy. Analyst. 132(1): 48-53.

[97] Samuels AC, DeLucia FC Jr, McNesby KL, Miziolek AW (2003 Oct) Laser-induced breakdown spectroscopy of bacterial spores, molds, pollens, and protein: initial studies of discrimination potential. Appl Opt. 42(30): 6205-9.

[98] Bazalgette Courrèges-Lacoste G, Ahlers B, Pérez FR (2007 Dec 15) Combined Raman spectrometer/laser-induced breakdown spectrometer for the next ESA mission to Mars. Spectrochim Acta A Mol Biomol Spectrosc. 68(4): 1023-8.

[99] Paull PE, Hyatt BJ, Wassef W, Fischer AH (2011 Oct) Confocal laser endomicroscopy: a primer for pathologists. Arch Pathol Lab Med. 135(10): 1343-8.

[100] Stepp H, Sroka R (2010 Oct) Possibilities of lasers within NOTES. Minim Invasive Ther Allied Technol. 19(5): 274-80.

[101] Senges C, Wrbas KT, Altenburger M, Follo M, Spitzmüller B, Wittmer A, Hellwig E, Al-Ahmad A (2011 Sep) Bacterial and Candida albicans adhesion on different root canal filling materials and sealers. J Endod. 37(9): 1247-52.

[102] Majumdar JD, Manna I (2003) Laser processing of materials. Sadhana (Academy Proceedings in Engineering Sciences), 28 (3-4): 495-562.

[103] Bartels KA, Bovik AC, Crawford RC, Diller KR, Aggarwal SJ (1993) Selective laser sintering for the creation of solid models from 3D microscopic images. Biomed Sci Instrum. 29: 243-50.

[104] Niino T, Hamajima D, Montagne K, Oizumi S, Naruke H, Huang H, Sakai Y, Kinoshita H, Fujii $\mathrm{T}(2011$ Sep) Laser sintering fabrication of three-dimensional tissue engineering scaffolds with a flow channel network. Biofabrication. 3(3): 034104.

[105] Torres K, Staśkiewicz G, Śnieżyński M, Drop A, Maciejewski R (2011 Feb) Application of rapid prototyping techniques for modeling of anatomical structures in medical training and education. Folia Morphol (Warsz). 70(1): 1-4.

[106] Suzuki M, Ogawa Y, Hagiwara A, Yamaguchi H, Ono H (2004) Rapidly prototyped temporal bone model for otological education. ORL J Otorhinolaryngol Relat Spec. 66(2): $62-4$. 
[107] Williams JV, Revington PJ (2010 Feb) Novel use of an aerospace selective laser sintering machine for rapid prototyping of an orbital blowout fracture. Int J Oral Maxillofac Surg. 39(2): 182-4.

[108] Schrank ES, Stanhope SJ (2011) Dimensional accuracy of ankle-foot orthoses constructed by rapid customization and manufacturing framework. J Rehabil Res Dev. 48(1): 31-42.

[109] Stoodley MA, Abbott JR, Simpson DA (1996 Apr) Titanium cranioplasty using 3-D computer modelling of skull defects. J Clin Neurosci. 3(2): 149-55.

[110] Bukharova TB, Antonov EN, Popov VK, Fatkhudinov TKh, Popova AV, Volkov AV, Bochkova SA, Bagratashvili VN, Gol'dshtein DV (2010 Jul) Biocompatibility of tissue engineering constructions from porous polylactide carriers obtained by the method of selective laser sintering and bone marrow-derived multipotent stromal cells. Bull Exp Biol Med. 149(1): 148-53.

[111] Iseri U, Ozkurt Z, Kazazoglu E (2011) Shear bond strengths of veneering porcelain to cast, machined and laser-sintered titanium. Dent Mater J. 30(3): 274-80.

[112] Dausinger F, Lichtner F, Lubatschowski H (2004) Femtosecond Technology for Technical and Medical Applications. Berlin Heidelberg: Springer-Verlag.

[113] Esser D, Rezaei S, Li J, Herman PR, Gottmann J (2011 Dec 5) Time dynamics of bursttrain filamentation assisted femtosecond laser machining in glasses. Opt Express. 19(25): 25632-42.

[114] Erdoğan M, Öktem B, Kalaycıoğlu H, Yavaş S, Mukhopadhyay PK, Eken K, Özgören K, Aykaç Y, Tazebay UH, Ilday FÖ (2011) Texturing of titanium (Ti6Al4V) medical implant surfaces with $\mathrm{MHz}$-repetition-rate femtosecond and picosecond $\mathrm{Yb}$-doped fiber lasers. Optics Express 19(11): 10986-10996

[115] Li Y, Gao Y, Shao B, Xiao J, Hu K, Kong L (2012 Jan 16) Effects of hydrofluoric acid and anodised micro and micro/nano surface implants on early osseointegration in rats. Br J Oral Maxillofac Surg. [Epub ahead of print]

[116] Aboushelib M, Salem N, Abotaleb A, Abd El Moniem N (2011 Sep 9) Influence of surface nano-roughness on osseointegration of zirconia implants in rabbit femur heads using selective infiltration etching technique. J Oral Implantol.. [Epub ahead of print]

[117] Nevins M, Kim DM, Jun SH, Guze K, Schupbach P, Nevins ML (2010 Jun) Histologic evidence of a connective tissue attachment to laser microgrooved abutments: a canine study. Int J Periodontics Restorative Dent. 30(3): 245-55.

[118] Pang W, Man HC, Yue TM (15 January 2005)Laser surface coating of Mo-WC metal matrix composite on Ti6Al4V alloy. Materials Science and Engineering. 390(1-2): 144-153.

[119] Prosecká E, Buzgo M, Rampichová M, Kocourek T, Kochová P, Vysloužilová L, Tvrdík D, Jelínek M, Lukáš D, Amler E (2012) Thin-layer hydroxyapatite deposition on a nanofiber surface stimulates mesenchymal stem cell proliferation and their differentiation into osteoblasts. J Biomed Biotechnol.2012: 428503.

[120] Steen MW, Mazumder J (2010) Laser Material Processing. London: Springer.

[121] Apotheker H, Nishimura I, Seerattan C (1984) Laser welded vs. soldered non precious alloy dental bridges: a comparative study. Laser Surg Med 4: 207-213. 
[122] Fornaini C, Bertrand C, Rocca JP, Mahler P, Bonanini M, Vescovi P, Merigo E, Nammour S (2010 Jul) Intra-oral laser welding: an in vitro evaluation of thermal increase. Lasers Med Sci. 25(4): 473-7.

[123] Fornaini C, Vescovi P, Merigo E, Rocca JP, Mahler P, Bertrand C, Nammour S (2010 Mar) Intraoral metal laser welding: a case report. Lasers Med Sci. 25(2): 303-7.

[124] Henderson R, Schulmeister K. (November 1, 2003) Laser Safety. New York, London: Taylor \& Francis. 


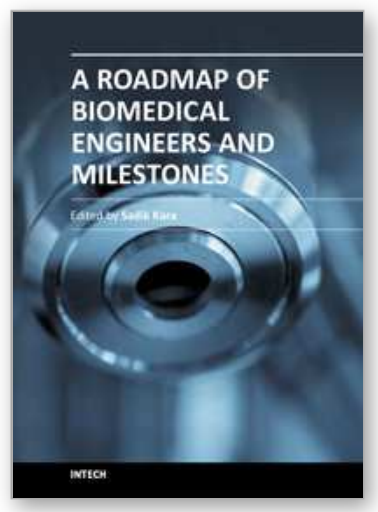

\author{
A Roadmap of Biomedical Engineers and Milestones \\ Edited by Prof. Sadik Kara
}

ISBN 978-953-51-0609-8

Hard cover, 230 pages

Publisher InTech

Published online 05, June, 2012

Published in print edition June, 2012

This book is devoted to different sides of Biomedical Engineering and its applications in science and Industry. The covered topics include the Patient safety in medical technology management, Biomedical Optics and Lasers, Biomaterials, Rehabilitat, Ion Technologies, Therapeutic Lasers \& Skin Welding Applications, Biomedical Instrument Aopplication and Biosensor and their principles.

\title{
How to reference
}

In order to correctly reference this scholarly work, feel free to copy and paste the following:

B. Cem Sener (2012). Biomedical Optics and Lasers, A Roadmap of Biomedical Engineers and Milestones, Prof. Sadik Kara (Ed.), ISBN: 978-953-51-0609-8, InTech, Available from: http://www.intechopen.com/books/aroadmap-of-biomedical-engineers-and-milestones/biomedical-optics-and-lasers

\section{INTECH}

open science | open minds

\section{InTech Europe}

University Campus STeP Ri

Slavka Krautzeka 83/A

51000 Rijeka, Croatia

Phone: +385 (51) 770447

Fax: +385 (51) 686166

www.intechopen.com

\section{InTech China}

Unit 405, Office Block, Hotel Equatorial Shanghai

No.65, Yan An Road (West), Shanghai, 200040, China

中国上海市延安西路65号上海国际贵都大饭店办公楼405单元

Phone: +86-21-62489820

Fax: $+86-21-62489821$ 
(C) 2012 The Author(s). Licensee IntechOpen. This is an open access article distributed under the terms of the Creative Commons Attribution 3.0 License, which permits unrestricted use, distribution, and reproduction in any medium, provided the original work is properly cited. 